\title{
Detection of Galactose and Glycerophospholipids by Galactose Biosensors and Advancement Their Proficiency Using Berkelium Colloidal Nanoparticles and Poly(3,4-Ethylenedioxythiophene)- Poly(Styrenesulfonate)-Based Biosensors
}

\author{
Alireza Heidari ${ }^{1,2,3,4,}{ }^{*}$
}

${ }^{1}$ Faculty of Chemistry, California South University, 14731 Comet St. Irvine, CA 92604, USA; ${ }^{2}$ BioSpectroscopy Core Research Laboratory, California South University, 14731 Comet St. Irvine, CA 92604, USA; ${ }^{3}$ Cancer Research Institute (CRI), California South University, 14731 Comet St. Irvine, CA 92604, USA; ${ }^{4}$ American International Standards Institute, Irvine, CA 3800, USA

\begin{abstract}
In the current paper, galactose-oxidase enzyme is used as stabilization medium due to its more proficiency, ability for more accurate controlling the enzyme reaction, protecting against wasting of enzyme as well as simple and easy use and exchange of enzyme medium after performing some levels of surface modification and developing multi-walled carbon nanotubes (MWCNTs) on Berkelium plate. For better connecting and stabilizing the enzyme on the medium, the prepared medium is washed by high concentration sulfuric acid and nitric acid and a large volume of deionized water and for protecting enzyme from devastating effect of Berkelium and prohibiting them to become inactive, surface is covered with cystamine before stabilization. Regarding the large size of galactose-oxidase enzyme compared to surface of medium, a connective material with amid at one end and pyrine at the other end is used as transfer agent and for stabilizing this connection, the prepared medium is placed into dimethylformamide (DMF) solution for a couple of hours. Activity of stabilized enzyme at $460(\mathrm{~nm})$ wavelength recorded by spectroscope was depicted against time to evaluate its stability in various times. The prepared medium, which have a large amount of galactose-oxidase enzyme, can be used as electrode in sensors. Furthermore, galactose-oxidase electrochemical sensor is one of the best methods for detecting low amount of galactose and applying Berkelium colloidal nanoparticles as a supplementary material in the structure of biosensor can be effective for advancement its proficiency and optimum proficiency. On the other hand, in the current study, electrode biosensor entitled as modified carbon paste electrode with Berkelium colloidal nanoparticles ( $\mathrm{Bk}_{\text {nano }} / \mathrm{CPE}$ ) is produced by carbon graphite powder, paraffin oil and Berkelium colloidal nanoparticles $(24 \mathrm{~nm})$ and it is compared with carbon paste electrode (CP). In semi-permeable membranes, a combination of 1 (ml) of $0.1(\mathrm{M})$ phosphate buffer with specified $\mathrm{pH}$ and $10(\mathrm{mg})$ of galactose-oxidase enzyme is placed around each electrode. In the same potential of $0.7(\mathrm{~V})$, biosensors are tested with galactose in concentration range of $(0-1)(\mathrm{mM})$ and various amounts of $\mathrm{pH}(4,6,8)$ which lead to producing the maximum current and tracing galactose in $\mathrm{pH}=6$ and concentration of $1(\mathrm{M})$ as the optimum condition. Currentmetry induced from both biosensors are compared and it is confirmed that using Berkelium colloidal nanoparticles in the structure of $\left(\mathrm{Bk}_{\text {nano }} / \mathrm{CPE}\right)$ electrode leads to increasing the conductivity and currentmerty of biosensor. In addition, qualitative and quantitative measurement of food components is of great importance due to high cost of traditional methods, in addition to tendency for more accurate and sensitive detecting of these components. galactose and glycerophospholipids are such compounds that they frequently measure. Various methods are used to detect these food elements. However, the necessity for accurate measurement of these two compounds with high sensitivity, especially for food health issue, leads to developing biological methods, especially biosensors. Among them, biosensors based on conductive polymer nanostructures, especially Poly(3,4-ethylenedioxythiophene)-poly(styrenesulfonate), have been recently interested due to their unique characteristics. The current paper aims to introduce and investigate the previously performed studies about Poly(3,4-ethylenedioxythiophene)-poly(styrenesulfonate)-based biosensors for detecting galactose and glycerophospholipids.
\end{abstract}

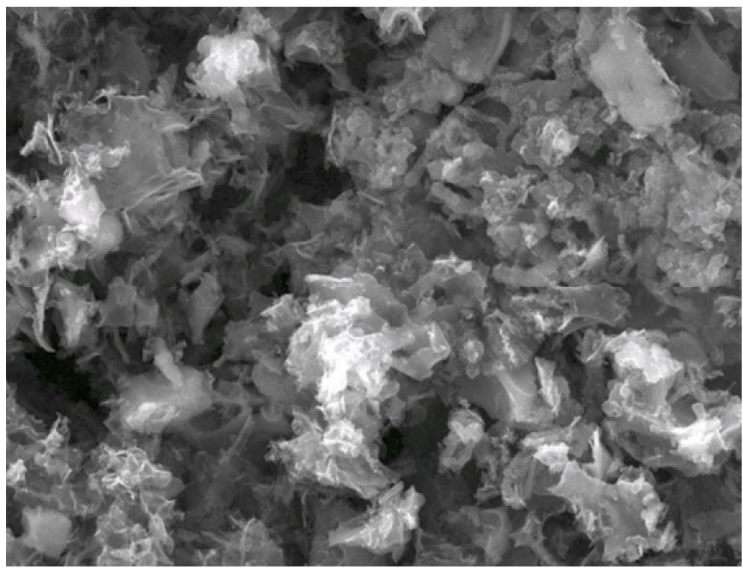

Scanning Electron Microscope (SEM) image of Berkelium colloidal nanoparticles with 50000x zoom.

Keywords: Multi-Walled Carbon Nanotubes (MWCNTs), Galactose-Oxidase Enzyme, Vapor Phase Precipitation, Biosensors, Berkelium Colloidal Nanoparticles, Currentmetry, Galactose, Glycerophospholipids, Poly(3,4-ethylenedioxythiophene)poly(styrenesulfonate) Nanofibers, Poly(3,4-ethylenedioxythiophene)-poly(styrenesulfonate) Nanotubes.

"Address correspondence to this author at the Faculty of Chemistry, California South University, 14731 Comet St. Irvine, CA 92604, USA; Tel: +1-775-410-4974; E-mail: Scholar.Researcher.Scientist@gmail.com; Alireza.Heidari@calsu.us 


\section{INTRODUCTION}

In recent decades, biosensors can be manufactured in very small scales (nanometer) as nanotechnology introduces into biological sciences. Nano-biosensors are very small sensors in nanometer scale that are able to detect special chemicals and or biological matters with very high accuracy and in completely selective form by stabilizing enzymes and or any other cell product on their surfaces [1-11].

Carbon nanotubes are one of the most frequent and appropriate nanostructures which can be used to make nano-biosensors due to their physical and chemical characteristics.

However, appropriate tests must be done to demonstrate their abilities. One of their clear advantages is that they have a large operational area, especially multi-walled carbon nanotubes (MWCNTs). Stabilizing the biological detectors such as enzymes over these materials may be led to increasing the proficiency of enzyme reaction, controllability of reaction, participation of more enzymes in reaction, prohibiting enzymes from wasting as well as information transferring with higher rate in these nanobiosensors [12-37].

Carbon nanotubes should be stabilized on a surface for better acting as the base of sensor. Stabilizing surfaces are mainly metallic. In the current paper, Berkelium plate is used for this purpose. Various methods have been used for developing and stabilizing carbon nanotubes on the medium. However, the most frequent method is chemical vapor deposition (CVD) [38-40].

Electrostatic, hydrophobic reactions and or covalent bond along with oxidization of nanotube are mainly used for stabilizing large enzymes on the surface of carbon nanotubes and a simple absorption on the external surface. In these types of bonds, a connective material is mainly used.

In the structure of nano-biosensors, the covered surface of medium by nanotubes is responsible for transferring the effects induced by reaction to transducer device for illustrating the signal. Carbon nanotubes can play two-side role, as the location of enzyme stabilization and as connective limit between reagent and transducer.

Biosensor technology is promisingly developed in bio-analytical researches. Sensors or biosensors are used for illustrating various analytes in various times. In 2012, glass carbon (GC) electrode biosensor, multiwalled carbon nanotube (MWCNT), titanium dioxide $\left(\mathrm{TiO}_{2}\right)$, apatite hydroxide and galactose-oxidase enzyme (GOX) were produced in China based on this technology. A chemical sensor is including receiver, transducer and separator. Receiver or biological element such as enzyme establishes a biological connection with measureable component. Transducer converts the measurable component to optical or electric signals and separator can acts as membrane. In 2012, an electrode biosensor was produced in South Africa based on glass carbon, multi-walled carbon nanotube (MWCNT), nickel nanoparticle and galactose-oxidase enzyme and the amount of galactose in the compound was measured using electric signals by ammeter. In 2011, a biosensor was produced in Taiwan based on glass carbon working electrode, glutaraldehyde (GA), carbon nanotube (multi-walled-gelatin) and galactose-oxidase enzyme (GOX). Galactose biosensor is one of the most successful biosensors in detecting chemical compounds such as galactose with very low amount. Its proficiency and sensitivity can be considerably increased by combining with various compounds such as Berkelium, Platinum, carbon nanotubes and so on. The currentmetry of these biosensors is based on the proficiency of galactose-oxidase enzyme (GOX) and electron exchange. In galactose-oxidase enzyme, oxidation and reduction groups of Flavin Adenine Dinucleotide (FAD) are oxidized and reduced and hence, it is necessary to establish a satisfactory electric relationship between active location of FAD enzyme and the surface of electrode to have a current. Amperometric galactose biosensors are mainly consisted of stabilizing galactose-oxidase enzyme in various media such as trapped polyacrylamide over working electrode surface. In the presence of galactose, oxygen and enzyme, as the biological catalyst of this system, the following reaction is performed:

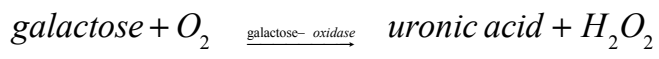

The presence of enzyme causes to consumption of oxygen by the galactose in the solution and reducing the oxygen penetration to the auxiliary Platinum electrode surface and it leads to producing compounds such as uronic acid and hydrogen peroxide. Decomposition of hydrogen peroxide near the standard electrode $(\mathrm{Ag} / \mathrm{AgCl})$ produces two free electrons, as shown in Eq. (2), which is the main reason for the 
current. Until the enzyme is stabilized and there is enough oxygen, the relationship between the current and the concentration of galactose is linear.

$$
\mathrm{H}_{2} \mathrm{O}_{2} \stackrel{(\mathrm{Ag} / \mathrm{AgCl})}{\longrightarrow} \mathrm{O}_{2}+2 \mathrm{H}^{+}+2 e^{-}
$$

Modification of working electrode using nanoparticles with various sizes can improves the proficiency of biosensors, increases the sensitivity and reduces the resistivity of electrode in the route of electron exchange. These nanoparticles can be made from Berkelium, Silver and Zinc which are widely used with various structures to modify the electric and conductivity properties of electrodes. Berkelium colloidal nanoparticles are metallic colloids and are used in various forms in the structure of electrode biosensors. Using Berkelium colloidal nanoparticles, the electric isolation effect is reduced in protein cortex of galactose-oxidase enzyme and electron exchange increases. The produced electron moves due to the effect of applying constant voltage on both sides of working and standard electrode and this electron movement leads to an electric current which can be measured by ammeter. The amount of exchanged electron and or the produced current indicates the amount of reacted galactose and its concentration in the sample. In the current paper, the proficiency of two biosensors in completely identical conditions are compared while the only difference between them is the presence of Berkelium colloidal nanoparticles in the electrode structure of one of them. These biosensors have different efficiencies in similar currentmetery condition and applying the Berkelium colloidal nanoparticles leads to increasing the conductivity and advancement the currentmetery.

Today, detecting the composition of foods through quality control tests is of great importance in food industries. High cost of traditional methods and the necessity for more accurate and sensitive measuring confirms the necessity of this issue. As a result, finding and or advancement faster, more accurate, more sensitive as well as cheaper measurement methods is always interesting for researchers and food producers.

The frequent analysis tools in food industries need to skillful operators and are time consuming. These tools are frequently needed to long separations, costly equipment and chemicals with high purity. A great part of these obstacles and problems can be removed by applying enzyme analyses. However, new food industries need to have small analysis tools to use easily in non-solution samples and to be able for simultaneous, online controlling one or more characteristics during synthesis process or food processing. Most of these necessities can be acceptably met using enzyme electrodes and hence, improves the proficiency and optimization of the process and the quality of product. Further, these enzyme electrodes should be cheap, reliable and strong and they should have obvious preferences over the available methods.

One of the most important reasons for cardiovascular diseases in recent years is high concentration of glycerophospholipids in blood. Glycerophospholipids are considerably found in dairy products and yolk and its concentration can be determined using chromatography methods such as high proficiency liquid chromatography (HPLC) and gas chromatography (GC) which are of appropriate sensitivity and selectivity. However, applying fast and efficient methods is of great importance as these methods are time consuming and costly. Therefore, enzyme methods such as glycerophospholipids esterase and glycerophospholipids oxidase can be practically used as alternatives of traditional chromatography methods due to their simplicity, being fast and effective.

Galactose is another important food component, which is frequently measured in quality control of food synthesis processes. Until now, various spectroscopy methods such as high proficiency liquid chromatography (HPLC) have been used for detecting galactose, especially in fermentation process of nectars. However, enzyme methods are widely developed to do this.

The tendency of researchers in food industries for measuring these compounds with repeatability, selectivity and high rate in very low concentrations in live environment leads to development of some tools entitled as biosensors so that $85 \%$ of frequent biosensors are used for galactose measurement.

Generally, sensors are tools for detecting a chemical, physical and or biological change and converting it to a measureable signal. A sensor is including a detector element, which is able to respond to the presence of a special analyte or a group of analytes. Another important part of a sensor is transducer that converts the created response to a sign. The third part of a sensor is signal processor which collects the received signal from transducer and after boosting it, finally illustrates it. 
Biosensors are a subset of chemical sensors, which have a completely especial proficiency in detecting biological processes. In this type of sensors, detector element is a biological compound such as protein, enzyme, antibody, nucleic acid, cell, tissue and or receiver which selectively reacts with the target analyte and creates a response. This response converts to a electric signal in transducer and after processing, the amount of this signal illustrates as voltage, current and or impedance. The amount of this signal relates to the concentration of analyte. Regarding the fact that the proficiency of biological detector elements is completely unique (for example, galactose-oxidase enzyme only oxidizes galactose), biosensors make it possible to quantitatively evaluate and to determine the concentration of analyte, in addition to qualitatively evaluation of analyte and determining the presence or absence of it. Figure (1) shows a schematic view of a biosensor.

The mentioned biological detector elements in aqueous solutions are of low durability on converter surfaces. For more durability, these materials should be stabilized over converter surfaces with some way. Surficial absorption of these compounds with converter surface, trapping in a matrix during covering the converter surface with this matrix and creation of covalent bond between these materials and converter surface are some methods which are used for this purpose. Among all these methods, the most effective and frequent method is trapping in matrix. These matrices are mainly including membranes, gel in carbon paste, graphite, silica and or polymer thin films. Undoubtedly, conductive polymer nanostructuresbased matrices, especially Poly(3,4-
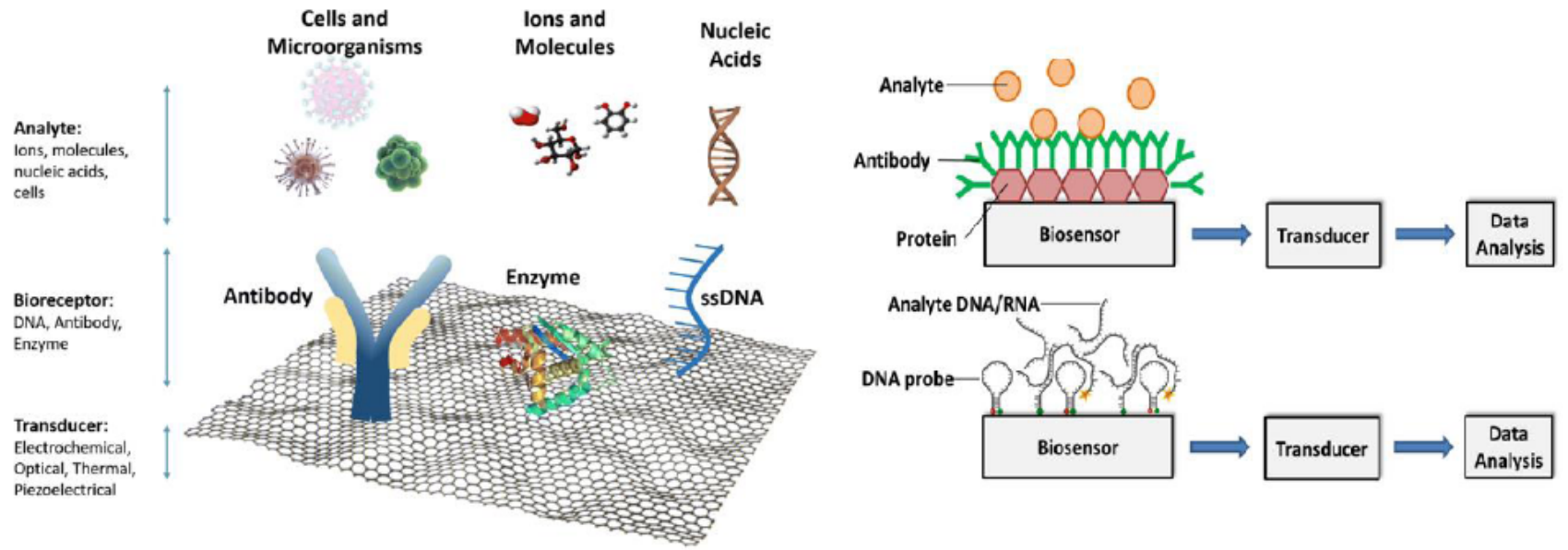

ethylenedioxythiophene)-poly(styrenesulfonate), are the most applicable and effective matrices due to high compatibility with biological components, ability for fast electron exchanging, considerably high effective area and appropriate cohesion. In the current research, the applications of Poly(3,4-ethylenedioxythiophene)poly(styrenesulfonate)-based nanobiosensors for measuring galactose and glycerophospholipids are discussed.

\section{MATERIALS AND METHODS}

In the current paper, three experimental steps are performed.

(i) Producing Berkelium plate covered by multiwalled carbon nanotubes (MWCNTs) and its preparation;

(ii) Preparing galactose-oxidase enzyme for stabilizing on the Berkelium plate;

(iii) Stabilizing galactose-oxidase enzyme using connective material PASE on the surface of carbon nanotubes and returning the activity of enzyme.

Galactose (with $98 \%$ purity and molecular weight of $198.17 \mathrm{gr} / \mathrm{mole}$ ), paraffin oil, dipotassium hydrogen phosphate $\left(\mathrm{K}_{2} \mathrm{HPO}_{4}\right)$ and potassium hydrogen phosphate $\left(\mathrm{KH}_{2} \mathrm{PO}_{4}\right)$ were supplied from Merck Co. for producing $0.1(\mathrm{M})$ phosphate buffer. Galactose-oxidase enzyme (35.5 (Ku/mg)) and Berkelium colloidal nanoparticles (Bk>48\% and about $24 \mathrm{~nm}$ ) were supplied from Sigma-Aldrich Corporation. Finally, carbon graphite powder (pure, mesh<325) was supplied from Sigma-Aldrich Corporation.

Figure 1: A schematic view of a biosensor. 


\subsection{Producing Berkelium Plate Covered by Multi- Walled Carbon Nanotubes (MWCNTs) and Its Preparation}

In this step, the following initial measures were performed for producing and preparing Berkelium plate:

\subsubsection{Preparation of Berkelium Plate}

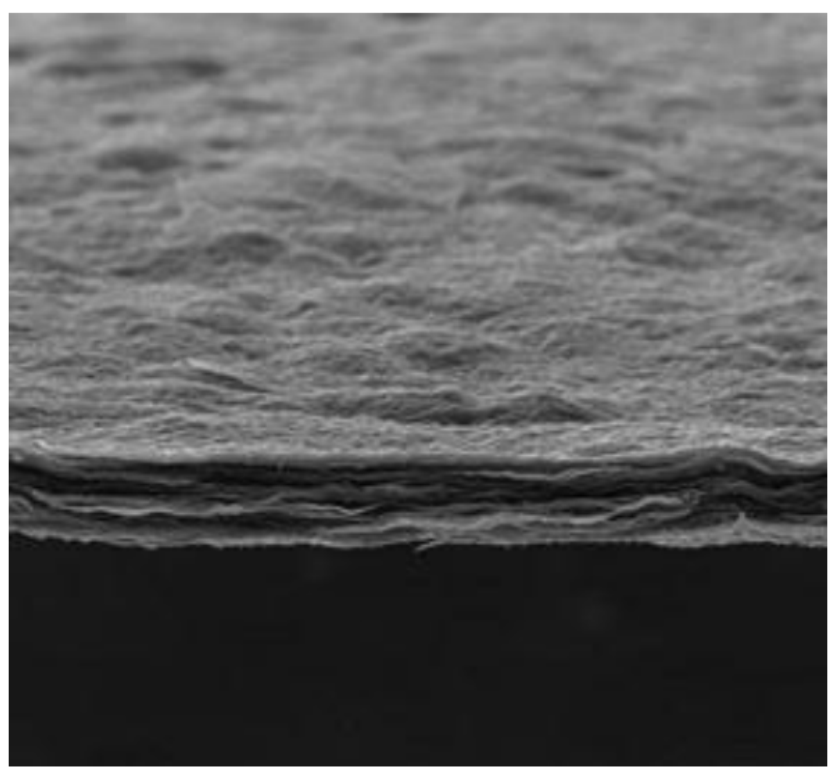

Figure 2: SEM image of a $10 \times 10(\mathrm{~mm})$ Berkelium plate with thickness of $1(\mathrm{~mm})$ was produced and its surface was completely covered using precipitation with homological vapors (Berkelium vapors) before any processing.
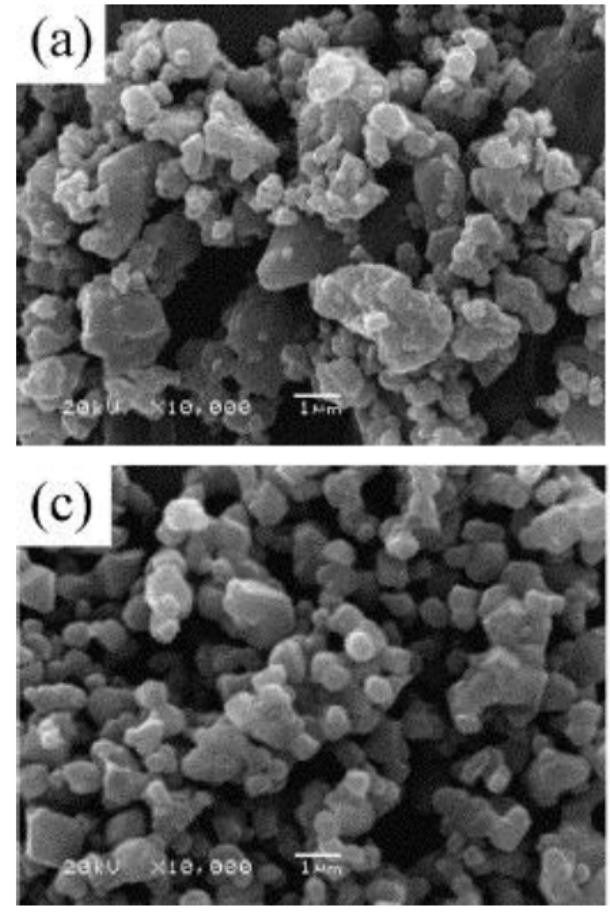

In this step, a $10 \times 10(\mathrm{~mm})$ Berkelium plate with thickness of $1(\mathrm{~mm})$ was produced and its surface was completely covered using precipitation with homological vapors (Berkelium vapors) before any processing (Figure (2)). Thickness of this homological layer is about 4-5 $(\mu \mathrm{m})$. Then, surface of Berkelium plate was washed in two stages with high concentration sulfuric acid $\left(\mathrm{H}_{2} \mathrm{SO}_{4}\right)$ and nitric acid $\left(\mathrm{HNO}_{3}\right)$ and finally with a large volume of deionized water for removing the remained impurities and wastes.

\subsubsection{Deposition of Catalyst Nickel Particles}

After preparing Berkelium plate, nickel catalyst was used for creating initial cores of carbon nanotubes and regular growing up of them. Catalyst particles in the size of about $4(\mathrm{~nm})$ were deposited over the surface with medium regularity and density using lithography method. (This step has been performed in Nanotechnology Laboratory, California South University (CSU)) (Figure (3))

\subsubsection{Development of Carbon Nanotubes (CNTs)}

For developing carbon nanotubes on the nickel nanoparticles stabilized on the Berkelium plate, CVD method was used. In this method, the prepared Berkelium plate was constantly placed into oven under vacuum condition and light hydrocarbon (methane with a percent of butane) was pumped to the oven as gas.
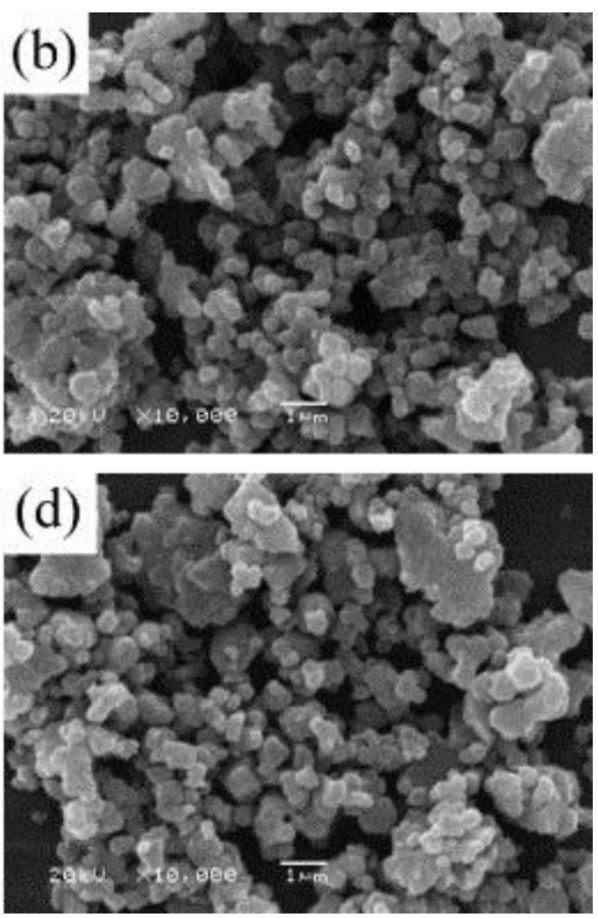

Figure 3: SEM images of Berkelium plate after preparing by catalyst particles in the size of about 4 (nm) were deposited over the surface with medium regularity and density using lithography method. 
Due to entering this gaseous compound and performing chemical reaction in the oven, carbon precipitants were emerged on the Berkelium medium and regular carbon nanotubes were produced. The developed nanotubes were multi-walled with diameter about (2-50) $(\mathrm{nm})$ and height of (15-20) (nm) were developed vertically on the medium, according to scanning electron microscopy (SEM) images (This operation have been performed in California South University (CSU) Nanotechnology Research Institute in cooperation with some professors and experts) (Figure (4)).

The area covered by these nanotubes is about (1015) $\left(\mathrm{mm}^{2}\right)$. Regarding the fact that each of these nanotubes acts as the base of sensor, it can be said that approximately $10^{8}-10^{9}$ sensor base are developed in the whole area of Berkelium medium $\left(100 \mathrm{~mm}^{2}\right)$. This amount of density is very appropriate for stabilizing biological detectors.

For removing the remained impurities and wastes on the plate during development process, surface of Berkelium plate was washed in two stages with high concentration sulfuric acid $\left(\mathrm{H}_{2} \mathrm{SO}_{4}\right)$ and nitric acid $\left(\mathrm{HNO}_{3}\right)$ and finally with a large volume of deionized water.

\subsection{Preparing Galactose-Oxidase Enzyme for Stabilizing on the Berkelium Plate}

Regarding high sensitivity of enzyme to environmental conditions and reaction situation and for maintaining active points of enzyme until the end of operation and correct connection of the prepared enzyme on the surface of medium (developed nanotube), very important and accurate measures were performed that are mentioned in the following.

\subsubsection{Preparing Galactose-Oxidase Apoenzyme}

For maintaining active points of enzyme until the end of operation, active points of enzyme were firstly separated and a coverage was place over the enzyme. This process was performed using separation of flavin adenine dinucleotide (FAD) from the structure of enzyme and preparing apoenzyme. To perform this process, a saturated solution of $\left(\mathrm{NH}_{4}\right)_{2} \mathrm{SO}_{4}$ was firstly prepared and then, its $\mathrm{pH}$ was decreased down to 1.4 in $20^{\circ} \mathrm{C}$ using high concentrated sulfuric acid $(97 \% \mathrm{v} / \mathrm{v})$. The galactose-oxidase enzyme solved in phosphate buffer with concentration of $20(\mathrm{mg} / \mathrm{mL})$ was added, drop by drop, during stirring to the saturated $20(\mathrm{~mL})$ solution in $5^{\circ} \mathrm{C}$. This solution was maintained in this temperature for half an hour and then, was centrifuged for 15 minutes in 20000 (rpm). The top yellow layer

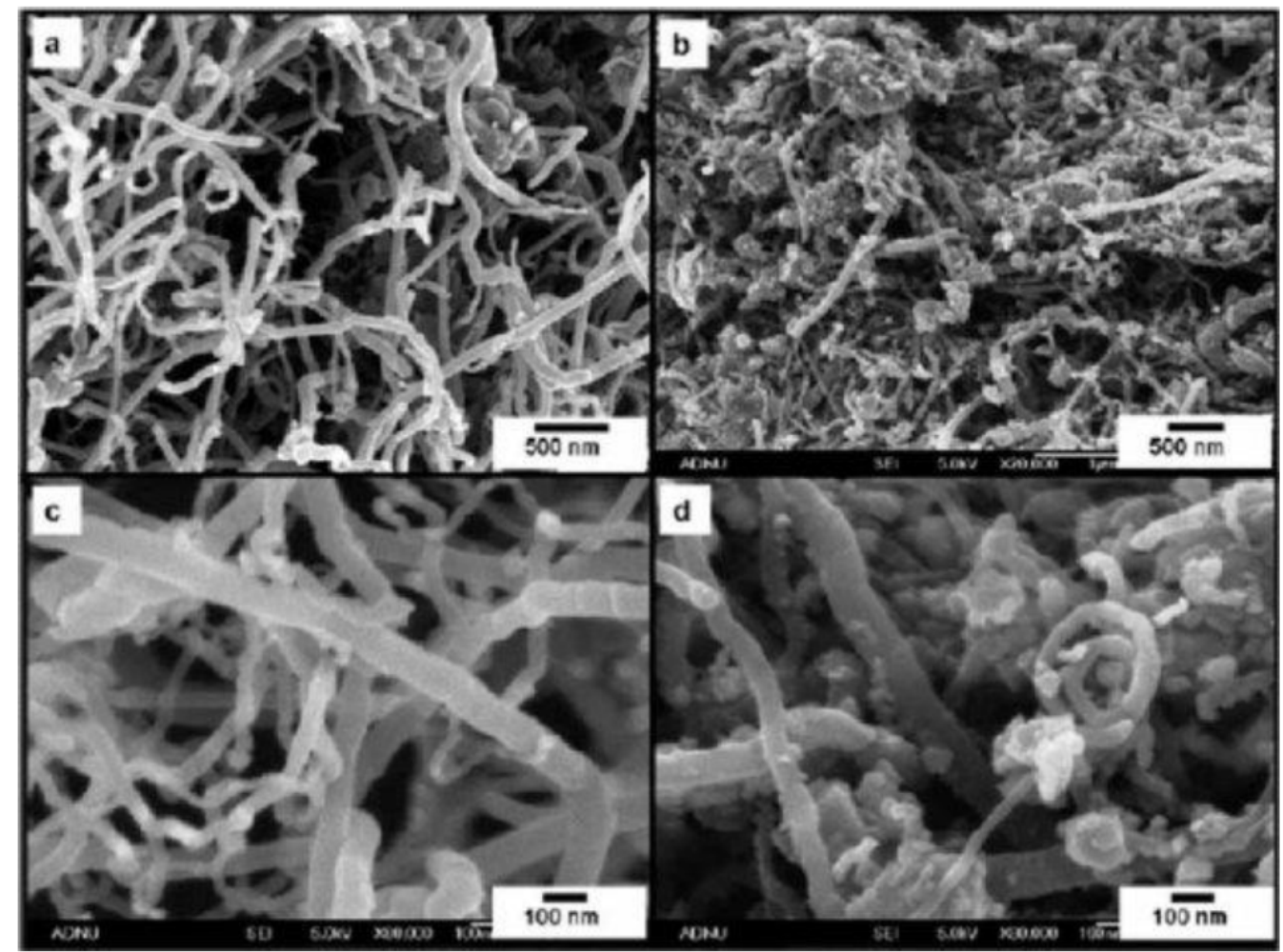

Figure (4): SEM images of the developed nanotubes were multi-walled with diameter about (2-50) (nm) and height of (15-20) $(\mathrm{nm})$ were developed vertically on the medium, according to scanning electron microscopy (SEM) image. 
was separated from the compound after centrifuging (Figure $(\mathbf{5 a}, \mathbf{5 b}, \mathbf{5} \mathbf{c})$ ) and the obtained precipitant (Figure $(\mathbf{5 d}, \mathbf{5 e})$ ) was repeatedly centrifuged in the same acidic $\mathrm{pH}$ condition for two times and the obtained precipitant was collected. The final precipitant was solved in phosphate buffer as the resource for galactose-oxidase apoenzyme (This step has been performed in Research Center of Biotechnology,
California South University (CSU)).

\subsection{Stabilizing Galactose-Oxidase Enzyme Using Connective Material PASE on the Surface of Carbon Nanotubes (CNTs) and Returning the Activity of Enzyme}

After performing all above mentioned steps, enzyme and medium were separately prepared for stabilizing.
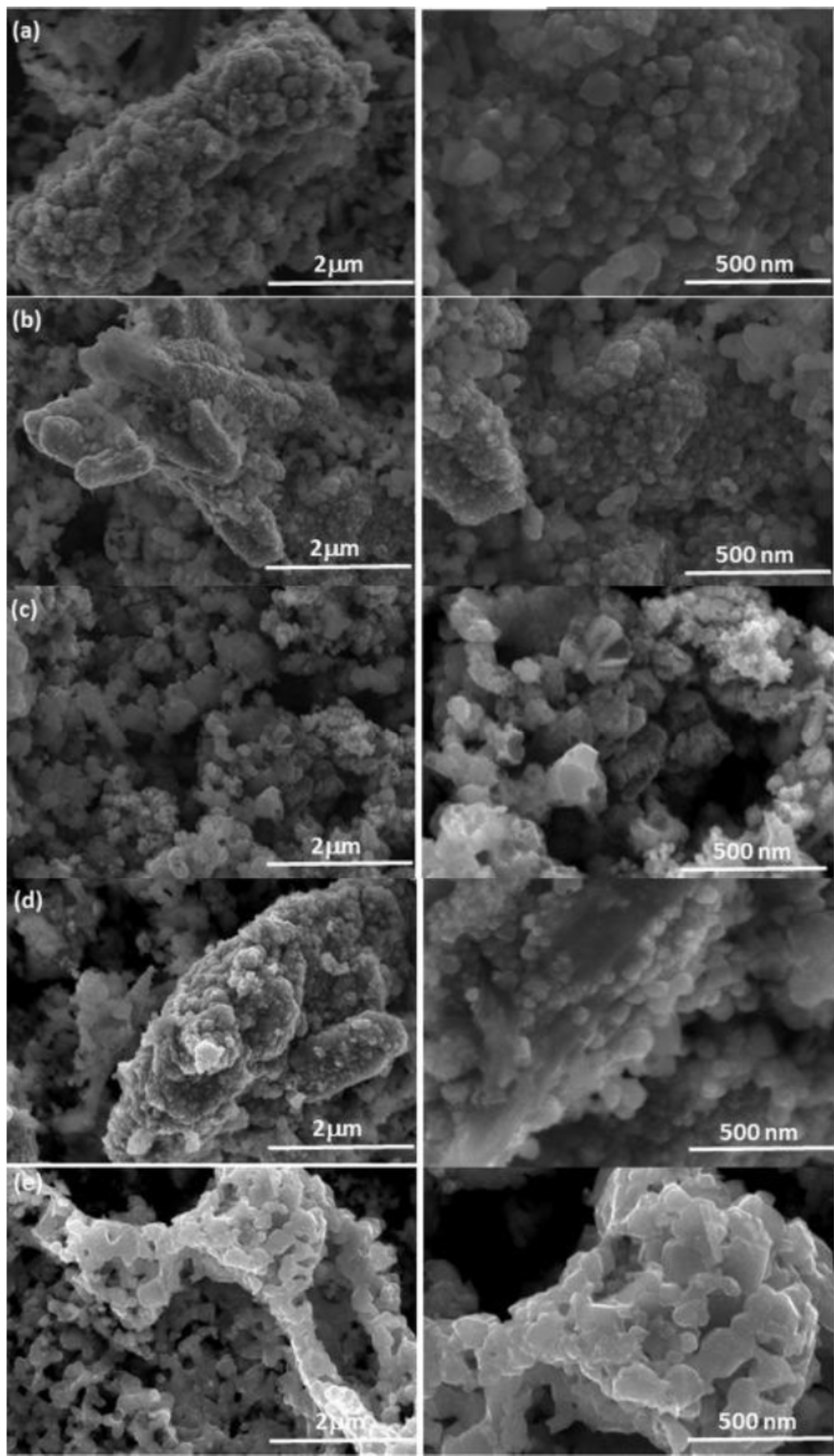

Figure 5: SEM images of the top yellow layer was separated from the compound after centrifuging $(\mathbf{a}, \mathbf{b}, \mathbf{c})$ and the obtained precipitant (d, e)) was repeatedly centrifuged in the same acidic $\mathrm{pH}$ condition for two times and the obtained precipitant was collected. 
Regarding the fact that Berkelium electrode is used in the current paper and direct contact of enzyme and metal changes natural structure of enzyme, medium surface was covered with a layer of cystamine.

Mainly, protein added to the multi layers of cystamine in these processes for sensor manufacturing. Therefore, it is positively charged. As a result, it can create an electrostatic absorption with the negatively charged enzyme. Hence, the relationship between the enzyme and medium facilitates.

For stabilizing galactose-oxidase enzyme on the developed carbon nanotubes on the Berkelium plate, pyrenebutanoic acid succinimidyl ester (PASE) is used in the current paper as connective material which has a pyrene group for making Van der Waals bond with carbon nanotubes and an amid group for connecting to the enzyme.

To accurate stabilization, the prepared medium was firstly stirred in a solution of connective material with concentration of $2.3(\mathrm{mg} / \mathrm{mL})$ and DMF and after 2 hours, medium was exited from the solution and washed with pure DMF and at the same time, the prepared apoenzyme was solved in screened and deionized water with concentration of $10(\mathrm{mg} / \mathrm{mL})$.

Then, the washed medium was contacted to apoenzyme solution for 18 hours and finally, medium was washed with very clear water for 6 times to remove all impurities produced during the process.

\subsubsection{Returning the Activity of Stabilized Enzyme on the Medium}

Regarding the fact that enzyme was changed to apo for protecting against loss of enzyme activity during stabilization steps, it is necessary to activate enzyme by returning the removed $F A D$ molecule to the structure of enzyme after stabilization process.

To perform this step, $200(\mu \mathrm{M})$ of FAD molecule obtained from changing enzyme to apoenzyme was incubated for 1 hour in 0.1 (M) phosphate buffer with concentration of $150(\mu \mathrm{g} / \mathrm{mL})$ and $\mathrm{pH}=6$ at room temperature. This process forms the stable complex of FAD protein which in fact is reconstructed enzyme. Its separation constant is very small $(k<10 M)$ and can be very effective for returning enzyme activity.

\subsubsection{Investigating the Activity of Stabilized Enzyme on the Medium}

After performing the stabilizing operation, enzyme activity of the incubated mixture was measured in the following form after placing in room temperature for 30 minutes to determine and confirm the retuning of enzyme activity.

In this method, the prepared medium was placed in solution containing potassium phosphate measuring buffer (measuring buffer is prepared by solving $0.1(\mathrm{ml})$ of $1 \%$ o-Dianisidine indicator in $12(\mathrm{ml})$ phosphate buffer with concentration of $0.1(\mathrm{M})$ and the $\mathrm{pH}=6.0$ ), $10(\mu \mathrm{L})$ of $18 \%$ galactose (in water), $10(\mu \mathrm{L})$ of peroxidase enzyme with $200(\mu \mathrm{g} / \mathrm{mL})$ concentration and $10(\mu \mathrm{L})$ of galactose-oxidase enzyme (dilution of 200 times) with concentration of $1(\mathrm{mg} / \mathrm{mL})$ and the amount of solution absorbed in wavelength of $460(\mathrm{~nm})$ was measured by JENWAY 6305 spectroscope (available in Laboratory of Microbiology, California South University (CSU)) in various times (Figure (6)). (Absorption value indicates the amount of galactose consumed by enzyme and hence enzyme activity).

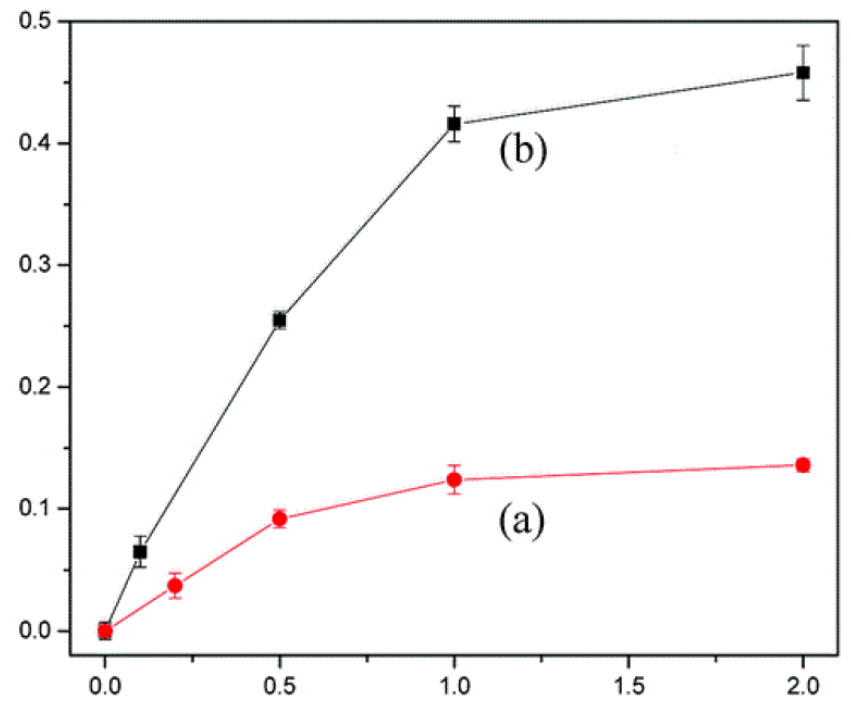

Figure 6: Enzyme activity (a) before (red curve) and (b) after (black curve) stabilizing operation process according to time which shows stable and activation of the enzyme after stabilizing.

\subsection{Electrode Preparation}

Firstly, carbon graphite powder was placed into oven for 30 minutes in $700^{\circ} \mathrm{C}$ so that volatile and absorptive materials remove from graphite powder and surface activity increases. Then, it was place in desiccator for 1 hour. This powder is the raw material for producing the electrode. CP (Carbon Paste) is produced by adding $100(\mathrm{mg})$ of carbon graphite powder to $36(\mu \mathrm{l})$ of paraffin oil, according to [40-50]. The modified CP with Berkelium colloidal nanoparticles is produced by adding $300(\mu \mathrm{l})$ of Berkelium colloidal 
nanoparticles to $100(\mathrm{mg})$ of carbon graphite powder and after evaporation of water in desiccator for 3 hours, $36(\mu \mathrm{l})$ of paraffin oil is added to it. By entering a part of these mixtures, separately, in glassy tubes with inner diameter of $4(\mathrm{~mm}), \mathrm{CPE}$ electrode and $\left(\mathrm{Bk}_{\mathrm{nano}} / \mathrm{CPE}\right)$ were prepared and electric connection with ammeter was established through a copper wire placed into the electrodes. When these electrodes are not useable, they are maintained at $4^{\circ} \mathrm{C}$.

\subsection{Enzyme Preparation and Biosensor Synthesis}

By oxidation of galactose with galactose-oxidase enzyme and synthesis of uronic acid, $\mathrm{pH}$ of the reaction environment is reduced. To prohibit severely variations of $\mathrm{pH}$ and maintaining the activity of enzyme, a specified amount of it is placed into phosphate buffer. To prepare 0.1 (M) phosphate buffer, $\mathrm{K}_{2} \mathrm{HPO}_{4}$ and $\mathrm{KH}_{2} \mathrm{PO}_{4}$ are used and its $\mathrm{pH}$ is set with $\mathrm{H}_{3} \mathrm{PO}_{4}$ and $\mathrm{NaOH}$. Separately, $10(\mathrm{mg})$ of galactose-oxidase enzyme was added to $1(\mathrm{ml})$ of $0.1(\mathrm{M})$ phosphate buffer (PBS) in semi-permeable membranes and it is fastened around each CPE electrode and ( $\left.\mathrm{Bk}_{\text {nano }} / \mathrm{CPE}\right)$. Then, the produced biosensors are placed into galactose solution with concentration range of $(0-1)$ (mM) for currentmetery.

\section{CONDUCTIVE POLYMERS}

Conductive polymers are a type of organic materials which have electric conductivity. It seems that metals have electric conductivity and organic materials are dielectric while conductive polymers are of both properties. Another advantage of conductive polymers is their process ability; i.e. their ability to be solved or melted.

This characteristic causes that these polymers produce and use in various forms. In addition, these polymers are flexible due to their plastic nature. Further, their electric conductivity can be set.

The reason for their electric conductivity is their coupled bond structure. It means that the presented molecules in $\pi$ bonds of these structures can be moved along the polymerization chain and conduct the electric current. Figure (7) shows the coupled structure of some conductive polymers.

Among conductive polymers, Poly(3,4ethylenedioxythiophene)-poly(styrenesulfonate) has been more interesting for researchers than others due to its high electric conductivity, simple synthesis process, good environmental stability and unique chemical nature (oxidization/reduction). The previously

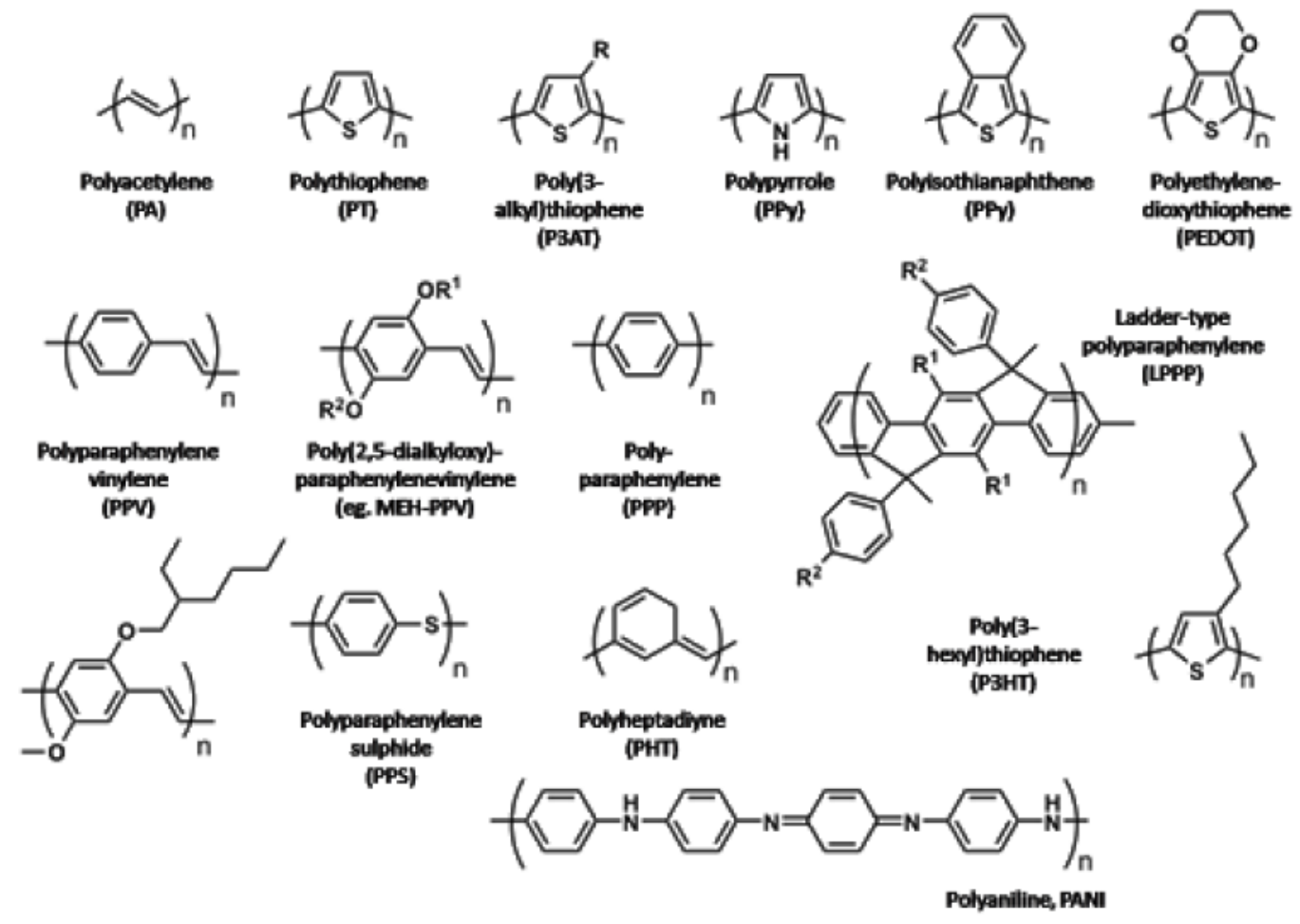

Figure 7: Coupled structure of some conductive polymers. 
performed studies in recent years about producing the Poly(3,4-ethylenedioxythiophene)-

poly(styrenesulfonate) in nano scale causes to advancement the most interesting property of this polymer, namely electric conductivity. In addition, increasing the effective area of polymer leads to improvement of its process ability and hence, application of this polymer increases in various sciences, especially food industries. Up to now, various types of Poly(3,4-ethylenedioxythiophene)poly(styrenesulfonate) nanostructures have been produced such as nanoparticles, nanofibers, nanotubes, nanowires, nanorods and nanobolts.

The above mentioned properties of conductive polymer nanostructures causes that these materials considering as one of the most interesting options for the stabilizing matrix of biodetector element on the transducer of biosensor. Among the produced nanostructures from Poly(3,4-ethylenedioxythiophene)poly(styrenesulfonate), nanoparticles, nanofibers and nanotubes of this material have been used in biosensors.

In the following sections, applications of these materials in the structure of biosensors as well as the methods used for measuring sugars, proteins and fats using these materials are discussed.

\section{BIOSENSORS}

As previously mentioned, biosensors are a type of sensors which have an amazing, unique proficiency in the presence of intervening factors. Stabilizing each biooperator on the transducer of biosensor leads to creation of a completely unique response to that analyte. Hence, biosensors are amazing tools from selectivity point of view.
Generally, analyte-biodetector element interaction in a biosensor causes to creation of a change in a parameter. This change converts to an electric signal by transducer and after processing, it illustrates.

\subsection{Bioelement Stabilizing Methods}

Till now, various physical and chemical methods have been proposed for stabilizing bioelements. However, they should be stabilized so that their active locations have not blocked and their geometrical form have not changed. In addition, it is necessary to have a relationship between biodetector element and sensitive area of transducer.

Trapping the enzyme in a matrix, e.g., an electropolymer film, is one of the most frequently used methods for stabilizing the enzyme. Another method is creating a covalent bond between protein and transducer surface in which, detector element is very high. These connections are established through function groups of detector element such as $\mathrm{SH}, \mathrm{OH}$, $\mathrm{COOH}$ and $\mathrm{NH}_{2}$, which are not necessary for biological reaction.

Surficial absorption is another method that is based on gravitational force between detector element and transducer surface and is used to stabilize detector elements. Lifespan of biosensor prepared by this method is very short. However, surficial absorption is very simple since it has no need to any other reagent and failure of enzyme is limited. Connecting the biological detector elements through electrostatic absorbers is another method for stabilizing these compounds. In this method, positive or negative charges are induced on transducer surface by applying a potential and then, biological detector element absorbs by the surface through electric induction. Figure (8) shows six most frequent types of methods used for stabilizing biosensor element.

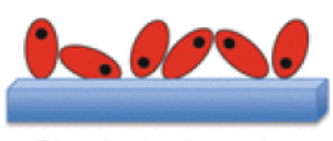

Physical adsorption

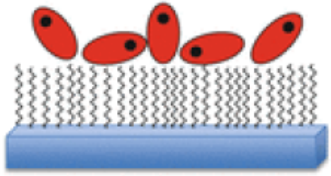

Non-oriented attachment to SAM

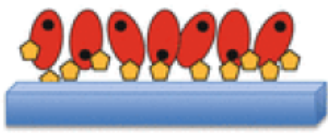

Inclusion of mediators

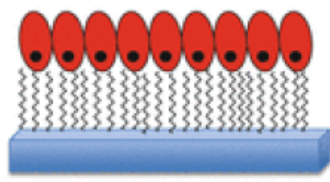

Covalent attachment to SAM

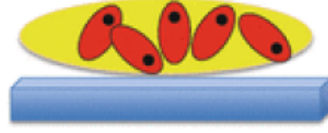

Conductive polymer entrapment

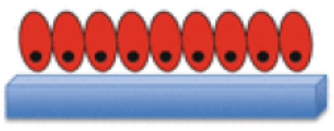

Direct covalent attachment

Figure 8: Six most frequent types of methods used for stabilizing biosensor element. 
Conductive polymer nanostructures can be used as stabilizer of biodetector elements due to their electric conductivity, compatibility with live materials, environmental stability and high contact surface.

\section{CYCLIC VOLTAMMETRY}

Cyclic voltammetry is an electrochemical method for detecting the presence of operational electroactive components, which are able to exchange electron in an electrochemical reaction in an aqueous environment, in a solution. Since the working process of the considered biosensors is based on an electrochemical reaction, cyclic voltammetry is an appropriate method for detecting the presence of an analyte in solution. In this regard, transducer of biosensor is used in this method as working electrode. In this method, working, auxiliary and standard electrodes are used. Standard electrode is of constant potential in various currents. Usually, Silver/chloride standard electrode is used. Auxiliary electrode is usually made from typical Platinum and working electrode is including transducer and polymer cover containing detector element.

After placing these three electrodes in the solution, a potential range between two specified values cyclically apply to working and standard electrodes and the currents obtained from working and auxiliary electrodes illustrate in terms of the applied potential. Therefore, a current against potential curve can be obtained. In this graph, current increases when potential reaches to a value in which an electroactive type can be oxidized and hence, a peak emerges in cyclic voltammetry graph.

When potential scanning applied in opposite direction, i.e. from higher values to lower ones, electroactive types with ability for reduction are reduced and create a peak in the current. Since each material has own specific potential (oxidizationreduction), analyte can be detected through this method. As a result, cyclic voltammetry method is used as the most important test for proficiency of transducer and sensor zone of biosensors. Figure (9) shows a schematic view of cyclic voltammetry device, potential application and the obtained cyclic voltammetry graph.

\section{GALACTOSE DETECTION}

In biosensors used for detecting galactose, the reactions performed on the bioelectrode (working electrode) are in the following form:

$$
\begin{aligned}
& \text { galactose } \underline{\mathrm{GOX}} \quad \mathrm{C}_{6} \mathrm{H}_{10} \mathrm{O}_{6}+\mathrm{H}_{2} \mathrm{O}_{2} \\
& \mathrm{H}_{2} \mathrm{O}_{2} \rightarrow \mathrm{H}_{2}+\mathrm{O}_{2}+2 e^{-}
\end{aligned}
$$

Heidari et al. [50-63] were investigated the biosensors that are used for detecting galactose based on galactose-oxidase stabilizing in Poly(3,4ethylenedioxythiophene)-poly(styrenesulfonate)

nanowires. In this method, aniline monomers are firstly polymerized in a product containing ammonium peroxide disulphate as oxidizer and then, they are precipitated on a carbon electrode as a film. When Poly(3,4-ethylenedioxythiophene)-

poly(styrenesulfonate) particles are growing up, polymerization of aniline continues by applying a potential. Then, Poly(3,4-ethylenedioxythiophene)poly(styrenesulfonate) nanowires are produced by applying a constant current to carbon electrode. Afterwards, this electrode places in a phosphate buffer solution $\quad(\mathrm{pH}=7.2) \quad$ and $\quad$ Poly(3,4ethylenedioxythiophene)-poly(styrenesulfonate) nanowires reduce by applying a constant potential. This causes that anions remove from the surface of
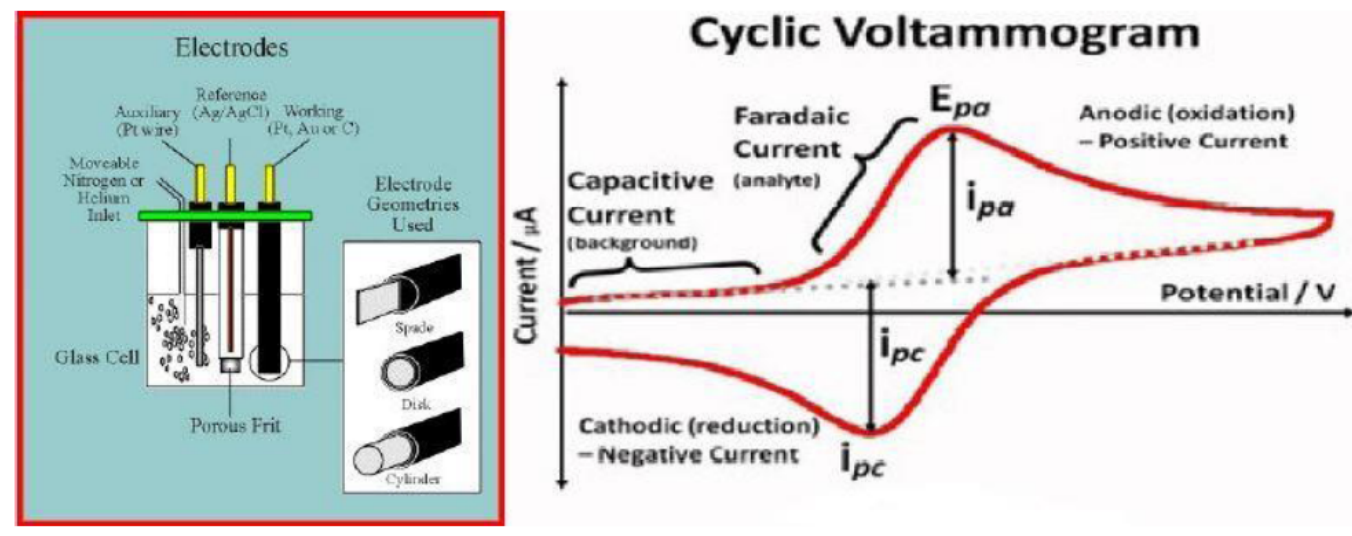

Figure 9: A schematic view of cyclic voltammetry device, potential application and the obtained cyclic voltammetry graph. 
Poly(3,4-ethylenedioxythiophene)-

poly(styrenesulfonate) and the appropriate conditions for surface absorbing of galactose-oxidase prepares. Then, electrode is placed in a phosphate buffer solution containing $2.5(\mathrm{mg} / \mathrm{l})$ galactose-oxidase and by applying $0.25(\mathrm{~V})$, positive charge induces on Poly(3,4ethylenedioxythiophene)-poly(styrenesulfonate) nanowires. This positive charge causes to electrostatic absorption of galactose-oxidase induced from negative surface charges. Figure (10) schematically shows this process.

In order to investigate the proficiency of the produced electrode, cyclic voltammetry technique is used. The produced electrode was placed in solutions with and without galactose. The resulted voltammetry graph show that when galactose-oxidase is in stable state, the related oxide peaks are emerged while when

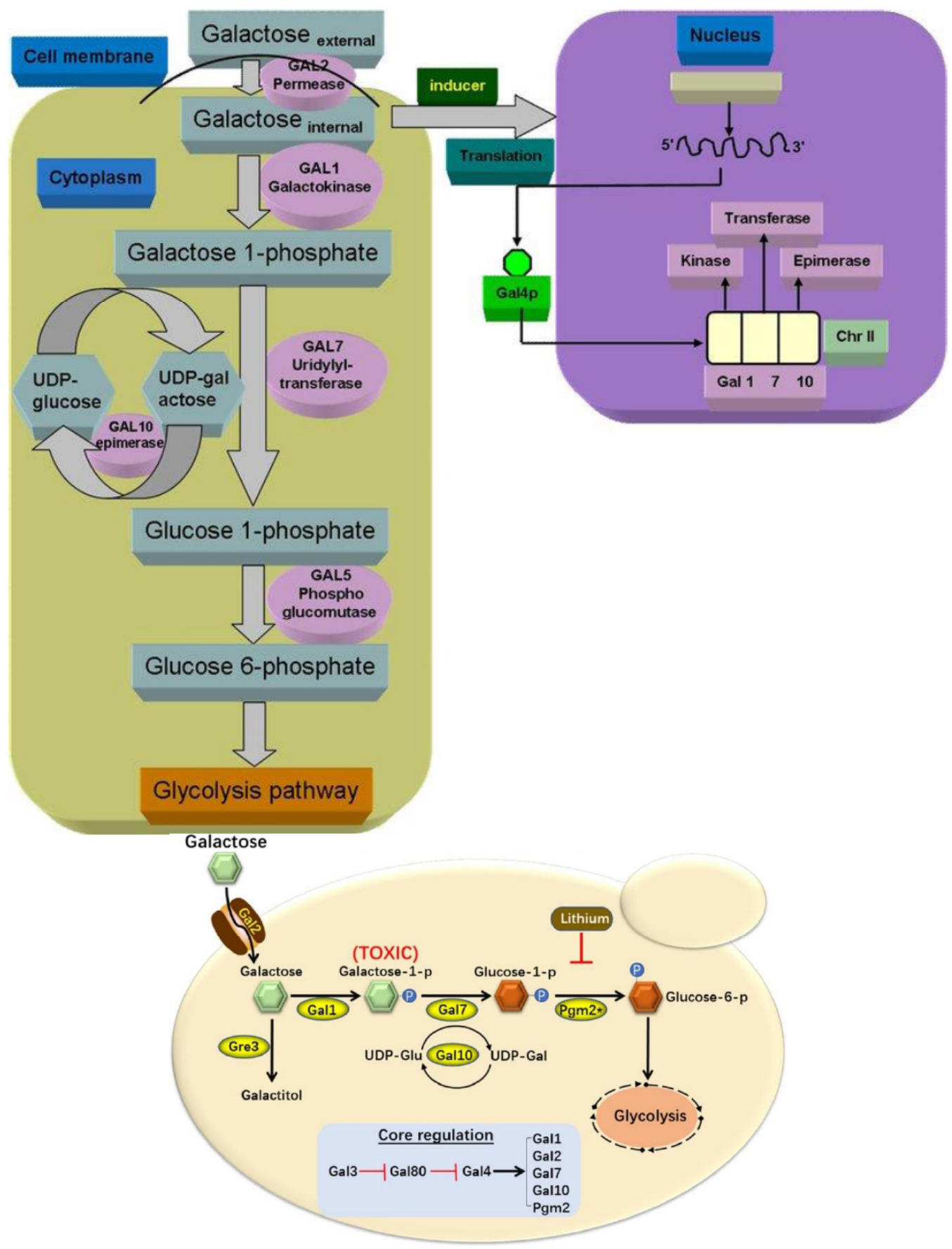

Figure 10: A schematic view of positive charge causes to electrostatic absorption of galactose-oxidase induced from negative surface charges. 
there is not enzyme, oxide peaks are not emerged (Figure (11)). This observation is performed for evaluating the correct proficiency of biosensor.

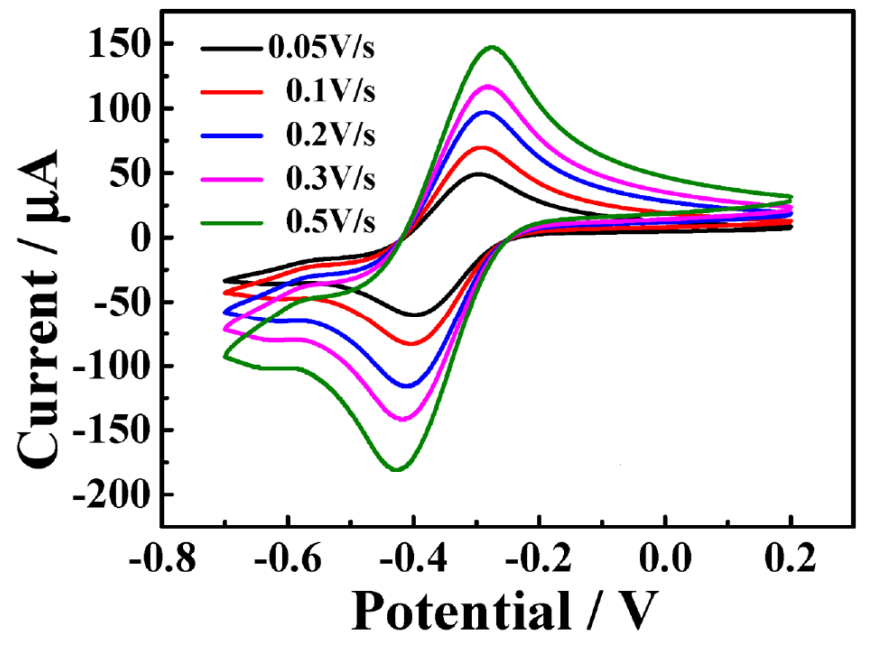

Figure 11: When galactose-oxidase is in stable state, the related oxide peaks are emerged while when there is not enzyme, oxide peaks are not emerged.

Another study was performed by Heidari et al. [6473] about the stabilizing of galactose-oxidase with Poly(3,4-ethylenedioxythiophene)-

poly(styrenesulfonate) nanotubes. In this study, a membrane of aluminum anodic oxidation with outer diameter of holes between 200 and $250(\mathrm{~nm})$ and inner diameter of holes equal to $100(\mathrm{~nm})$ was used to synthesize Poly(3,4-ethylenedioxythiophene)poly(styrenesulfonate) nanotubes.

Firstly, one side of aluminum anodic oxidation was covered with $10(\mathrm{~nm})$ thick Platinum layer through evaporation in vacuum. Then, a copper wire was connected to Platinum for conducting electric current. After isolating the copper wire and backside of Platinum for prohibiting their incident with the solution containing the sample, the produced electrode was placed in a solution containing 0.5 (M) sulfuric acid and 0.2 (M) aniline monomer. By applying scanning potential, aniline polymerization and Poly(3,4ethylenedioxythiophene)-poly(styrenesulfonate)

precipitation in holes of aluminum anodic oxidation were performed and Poly(3,4-ethylenedioxythiophene)poly(styrenesulfonate) nanotubes were produced.

In order to stabilize galactose-oxidase, Poly(3,4ethylenedioxythiophene)-poly(styrenesulfonate)

nanotubes were reduced in phosphate buffer solution through applying $250(\mathrm{mV})$ so that the anions around the Poly(3,4-ethylenedioxythiophene)poly(styrenesulfonate) nanotubes were removed. Then,
Poly(3,4-ethylenedioxythiophene)-

poly(styrenesulfonate) nanotubes were oxidized in phosphate buffer solution containing 7 (mg/l) galactose-oxidase under $750(\mathrm{mV})$ to electrostatically absorb galactose-oxidase. During oxidation, galactoseoxidase which is of negative charge absorbs in inner wall of Poly(3,4-ethylenedioxythiophene)poly(styrenesulfonate) nanotubes and traps. Then, electrode was washed by distilled water to remove enzymes that are not appropriately absorbed by inner wall of nanotubes.

In order to investigate the proficiency of the produced electrode, cyclic voltammetry technique was used.

\section{GLYCEROPHOSPHOLIPIDS DETECTION}

In biosensors used for detecting glycerophospholipids, the reactions performed on the bioelectrode are in the following form:

$$
\begin{aligned}
& \text { glycerophospholipids }+\mathrm{O}_{2} \rightarrow \\
& \text { glycerophospholipids - ten-30ne }+\mathrm{H}_{2} \mathrm{O}_{2} \\
& \mathrm{H}_{2} \mathrm{O}_{2} \rightarrow 2 \mathrm{H}^{+}+\mathrm{O}_{2}+2 e^{-}
\end{aligned}
$$

Heidari et al. [74-83] were used Poly(3,4ethylenedioxythiophene)-poly(styrenesulfonate)

nanotubes for stabilizing lipase enzyme in biosensors used for detecting glycerophospholipids. In this method,

Poly(3,4-ethylenedioxythiophene)poly(styrenesulfonate) nanotubes (PANI-NT) were firstly produced through chemical polymerization reaction. Then, these nanotubes were precipitated on the surface of (indium-tin) oxide electrode by electrophoretic method as a film. Then, the produced electrode was place into a solution containing glutaraldehyde (GLU). The reason for using glutaraldehyde is that this compound is of carbonyl group in both ends. It can bond with nitrogen of Poly(3,4-ethylenedioxythiophene)-

poly(styrenesulfonate) film on the surface of (indiumtin) oxide from one end and connects to nitrogen groups of lipase at the other end. Therefore, lipase stabilizes on the Poly(3,4-ethylenedioxythiophene)poly(styrenesulfonate) films, covalencely. After connecting glutaraldehyde to the film surface, electrode dries and enters to lipase solution and after sometime, electrode dries.

In this investigation, the proficiency of the produced electrode was evaluated by cyclic voltammetry. In this 
study, three types of electrode, ((PANI-NT)/ITO) (electrode covered with carbon nanotubes without glutaraldehyde and or lipase), (PANI/GLU/ITO) and ((LIP/GLU/PANI)-(NI-ITO)) were compared in environments with and without glycerophospholipids. Observing the peaks related to reaction of lipase and glycerophospholipids available in sample container for electrode and disappearing them in two other states confirms the correct proficiency of electrode.

In a similar study, Heidari et al. [83-99] were produced biosensors for detecting glycerophospholipids based on Poly(3,4ethylenedioxythiophene)-poly(styrenesulfonate) films covered on electrode of (indium-tin) oxide by electrochemical method.

In this study, Poly(3,4-ethylenedioxythiophene)poly(styrenesulfonate) was firstly covered on electrode of (indium-tin) oxide by electrochemical polymerization and then, all steps performed by Heidari et al. were repeated [100-113].

In another investigation, Heidari et al. [114-125] were produced glycerophospholipids biosensor through simultaneous stabilizing the glycerophospholipidsoxidase and glycerophospholipids-esterase on Poly(3,4-ethylenedioxythiophene)-

poly(styrenesulfonate) films. In this method, Poly(3,4ethylenedioxythiophene)-poly(styrenesulfonate) was firstly covered on electrode of (indium-tin) oxide through electrochemical polymerization. Then, $1 \%$ glutaraldehyde was distributed over Poly(3,4ethylenedioxythiophene)-poly(styrenesulfonate) films and allows that surface to be dried. Then, glycerophospholipids-esterase was distributed over dried surface of electrode and after it became dry, glycerophospholipids-oxidase was distributed and dried. Then, this (enzyme-polymeric) set was washed by distilled water for removing oligomers and not stabilized enzymes. The results obtained from cyclic voltammetry confirm the presence of glycerophospholipids and glycerophospholipids oleate.

\section{RESULTS AND DISCUSSION}

\subsection{Currentmetery}

Currentmetery of biosensors is performed separately through standard $(\mathrm{Ag} / \mathrm{AgCl}), \mathrm{CPE}$ and $\left(\mathrm{Bk}_{\text {nano }} / \mathrm{CPE}\right)$ electrodes in room temperature. Galactose solution with specified concentrations were prepared for currentmetery of biosensors and the produced current was measured by ammeter by applying the same potential $0.7(\mathrm{~V})$ to both biosensors.

Figure (12) shows the currentmetery of biosensor in terms of galactose concentration with different efficiencies of $\mathrm{CPE}$ and $\left(\mathrm{Bk}_{\text {nano }} / \mathrm{CPE}\right)$ electrodes. The curves show that the concentration of substrate (galactose) affects the activity of galactose-oxidase enzyme. In very low concentrations of substrate, not all active locations of enzyme fill with substrate and the activity of enzyme would be low. By gradual increasing the concentration of substrate, enzyme activity increases until reaching to a specified concentration in which all active locations of enzyme fill with substrate and enzyme activity reaches to its maximum amount under operational condition. In this Figure, curve $b$ (proficiency of $\left(\mathrm{Bk}_{\text {nano }} / \mathrm{CPE}\right)$ electrode) is of higher currents than curve a (proficiency of CPE electrode) due to having Berkelium colloidal nanoparticles. The maximum current response of $\mathrm{CPE}$ and $\left(\mathrm{Bk}_{\text {nano }} / \mathrm{CPE}\right)$ electrodes in phosphate buffer with $\mathrm{pH}=4$ is 0.4 and 1.2 $(\mu \mathrm{A})$, respectively, which show different proficiency of two electrodes in similar potential and $\mathrm{pH}$. In Figure (13), currentmetery of biosensor in terms of the concentration of galactose is shown for two different efficiencies of CPE and ( $\mathrm{Bk}_{\text {nano }} / \mathrm{CPE}$ ) electrodes. In this Figure, upper curve (red curve) (proficiency of ( $\mathrm{Bk}_{\text {nano }} / \mathrm{CPE}$ ) electrode) is of higher currents than lower curve (black curve) (proficiency of CPE electrode) due to having Berkelium colloidal nanoparticles.

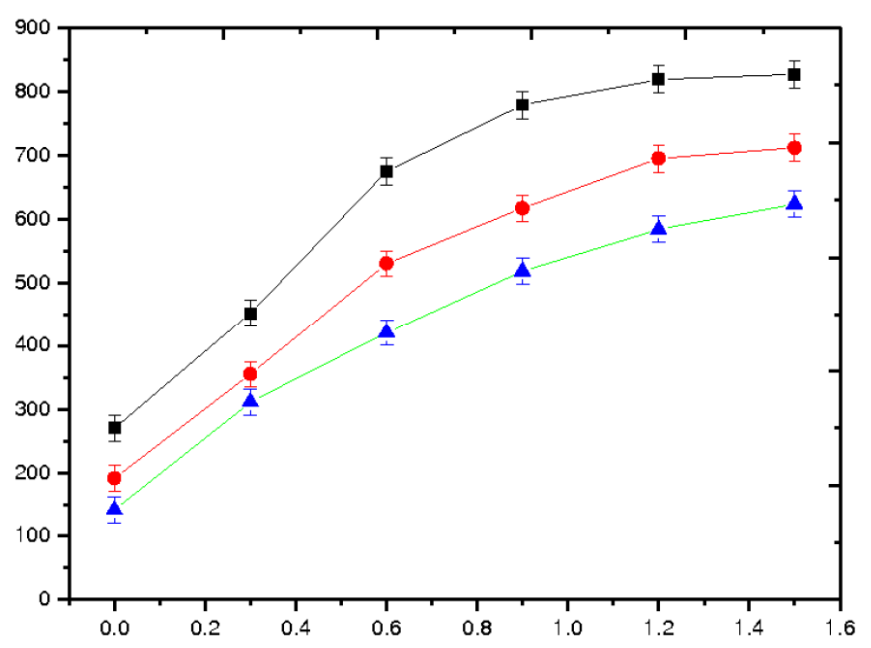

Figure 12: Currentmetery of biosensor in terms of galactose concentration with different efficiencies of CPE and (Bknano/CPE) electrodes. 


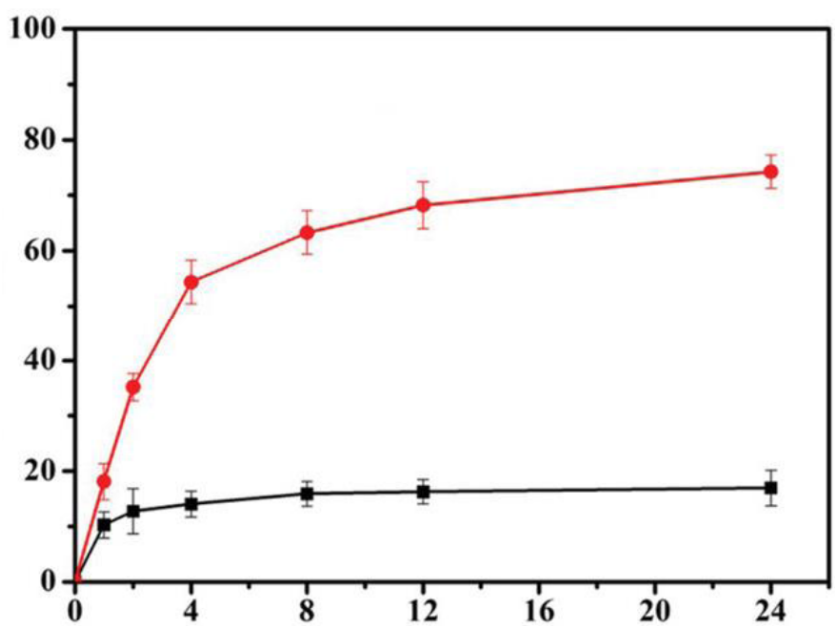

Figure 13: Currentmetery of biosensor in terms of the concentration of galactose is shown for two different efficiencies of CPE and ( $\left.\mathrm{Bk}_{\text {nano }} / \mathrm{CPE}\right)$ electrodes. In this Figure, upper curve (red curve) (proficiency of $\left(\mathrm{Bk}_{\text {nano }} / \mathrm{CPE}\right)$ electrode) is of higher currents than lower curve (black curve) (proficiency of CPE electrode) due to having Berkelium colloidal nanoparticles.

In addition, according to Figure (14), the maximum current response of $\mathrm{CPE}$ and $\left(\mathrm{Bk}_{\text {nano }} / \mathrm{CPE}\right)$ electrodes in phosphate buffer with $\mathrm{pH}=6$ is 0.7 and $1.58(\mu \mathrm{A})$, respectively, which show considerably different proficiency of two electrodes in similar potential and $\mathrm{pH}$.

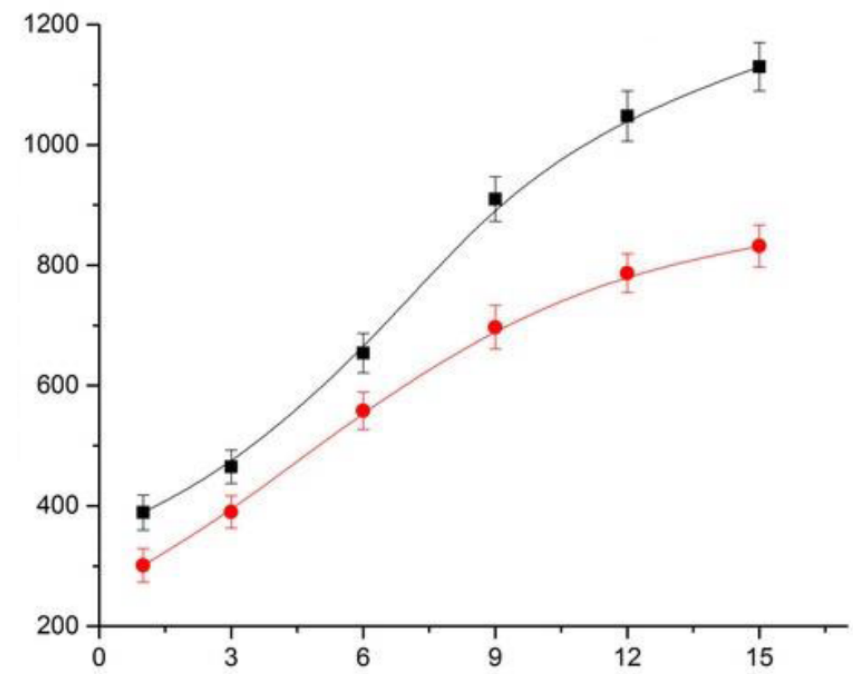

Figure 14: The maximum current response of CPE and $\left(\mathrm{Bk}_{\text {nano }} / \mathrm{CPE}\right.$ ) electrodes in phosphate buffer with $\mathrm{pH}=6$, which show considerably different proficiency of two electrodes in similar potential and $\mathrm{pH}$.

In Figure (15), currentmetery of biosensor in terms of the concentration of galactose is shown for two different efficiencies of $\mathrm{CPE}$ and $\left(\mathrm{Bk}_{\text {nano }} / \mathrm{CPE}\right)$ electrodes. According to this Figure, the maximum current response of $\mathrm{CPE}$ and $\left(\mathrm{Bk}_{\text {nano }} / \mathrm{CPE}\right)$ electrodes in phosphate buffer with $\mathrm{pH}=8$ is 0.6 and $1.1(\mu \mathrm{A})$, respectively. In this Figure, curve $b$ (proficiency of $\left(\mathrm{Bk}_{\text {nano }} / \mathrm{CPE}\right)$ electrode) is of higher currents than curve a (proficiency of CPE electrode) due to having Berkelium colloidal nanoparticles. It means that carbon electrode modified with Berkelium colloidal nanoparticles prepares appropriate environment for direct movement of electrons due to high electrocatalystic activity of nanoparticles, hence, leads to facilitation of electron movement, higher currents, and finally, better tracing of galactose due to higher conductivity. By evaluating these currentmeteries, the positive effect of Berkelium colloidal nanoparticles is confirmed and ( $\left.\mathrm{Bk}_{\text {nano }} / \mathrm{CPE}\right)$ electrode is selected as the appropriate electrode.

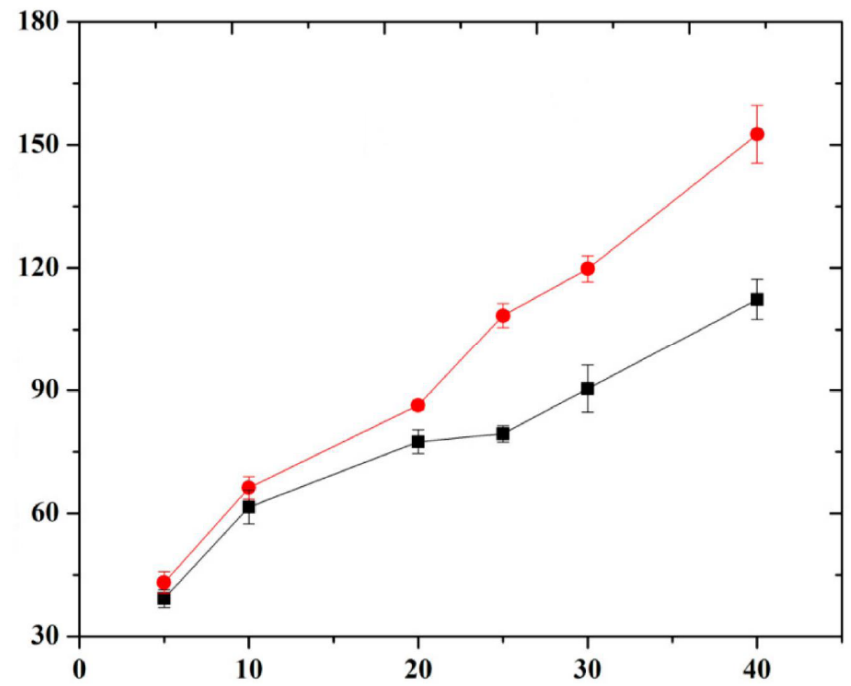

Figure 15: Currentmetery of biosensor in terms of the concentration of galactose is shown for two different efficiencies of CPE and ( $\left.\mathrm{Bk}_{\text {nano }} / \mathrm{CPE}\right)$ electrodes.

Using Figure (15) and comparing the illustrated graphs for various concentrations in variation of $\mathrm{pH}$ against current, it can be seen that maximum current is achieved in $\mathrm{pH}=6$ and increasing the concentration of galactose leads to producing higher ampere. It indicates that optimum condition is achieved in which, current is maximum and the amount of detected galactose is maximum.

\section{CONCLUSION}

After completing experimental steps, nanomedium was produced. This medium can be used as high accurate and sensitive nano-biosensor due to the stabilized enzyme on its surface. 
For protecting enzyme activity from devastating effects of metal media during stabilization processes, it is necessary to cover the medium surface with an appropriate material such as cystamine.

Removing the active points of enzyme (making apo) before the beginning of stabilization step is necessary for protecting the proficiency of enzyme.

Regarding the relatively large size of galactoseoxidase enzyme, this enzyme should be connected to outer wall of carbon nanotube using a connective material such as 1-pyrenebutanoic acid succinimidyl ester (PASE).

Regarding the fact that medium is placed into phosphate buffer and accurately washed after each measuring of activity, the possibility of the presence of free (non-stabilized) enzymes on the medium is very low and it can be assuredly said that the measured activity of about $280(\mathrm{u} / \mathrm{mg})$ at initial times shown in Figure (6) is only due to stabilized enzymes and it confirms that temporary removing of enzyme activity and returning its activity after completing the stabilizing steps cannot permanently inactivate enzymes although it can remove some enzymes from their third structure.

As can be seen in Figure (6), variation of activity of stabilized enzyme against time is not considerably changes compared to the activity of free enzyme. It confirms the stability of stabilized enzyme.

Creating medium density (mentioned in the paper) in developed nanotubes affects the penetration of enzyme and its stability.

Regarding the operational level, high conductivity and flexibility of carbon nanotubes compared to other metals, they are appropriate for stabilizing various chemical and biological detectors and utilizing them in manufacturing the biosensors lead to increasing the proficiency and sensitivity and decreasing the resistivity in proficiency.

In the current paper, galactose-oxidase biosensor is experimentally manufactured using carbon nanotubes based on the investigations performed about various previously performed researches in this field. Although these tests are performed similar to experimental studies in some steps, obtaining new results such as temporary inactivating the enzyme and using Berkelium plate, alone, in macro plate form as the medium is the differences of the current research with similar researches.
Although the performed studies in the field are in the level of initial manufacturing of these sensors, it leads to preparing an appropriate space for performing more developed research works in this field. Experimental researches performed in the current paper and the obtained results can be represented to researchers with this aim. Hopefully, more acceptable results will be achieved if more applicable plans will define.

Evaluations of the proficiency of biosensors with two different electrodes show that enzyme activity is low in very low concentrations of galactose for both biosensors. Then, by gradually increasing of galactose concentration, enzyme activity increases until reaching to a specified concentration in which all active locations of enzyme fill with substrate and enzyme activity reaches to its maximum amount. The results obtained from currentmetery of biosensors show that by increasing the concentration of galactose and after reaching it to a specified amount, enzyme activity reaches to a stage in which, its rate does not change with increasing the galactose concentration and remains constant. This phenomenon happens when all active locations of enzyme are occupied and there is not enough active space for oxidizing the available galactose. To maintain the activity of active points of galactose-oxidase enzyme, enzyme is located in phosphate buffer so that $\mathrm{pH}$ of reaction environment controls using buffer and enzyme activity maintains during oxidization. Investigation of the proficiency of biosensors in various $\mathrm{pH}$ values of phosphate buffer show that enzyme activity and currentmetery of both biosensors in phosphate buffer with $\mathrm{pH}=6$ are increased. This increasing in the activity is due to creation of an appropriate ionic state for substrate and or galactose-oxidase enzyme. Oxidation and reduction groups in galactose-oxidase enzyme, which are oxidized and reduced, deeply deposit in a hole and so, they are not easily available for guiding electrons towards electrode surface and this is against the proficiency of enzyme. Therefore, in establishing the current, it is necessary to prepare satisfactory electric relationship between active locations of enzyme (FAD) and surface of electrode. To solve this problem, Berkelium colloidal nanoparticles are used in the structure of $\left(\mathrm{Bk}_{\text {nano }} / \mathrm{CPE}\right)$ electrode. It leads to increasing the conductivity, facilitating the movement of electrons and increasing the satisfactory electric relationship between electrode surface and active locations of enzyme (FAD). Modification of $\left(\mathrm{Bk}_{\text {nano }} / \mathrm{CPE}\right)$ electrode with Berkelium colloidal 
nanoparticles leads to creation of a microenvironment like (oxidization-reduction) of proteins, which is due to high electrocatalystic activity of nanoparticles. It means that the isolation effect in protein cortex of enzyme is reduced and electron exchange is increased. Another reason for using Berkelium colloidal nanoparticles in the structure of $\left(\mathrm{Bk}_{\text {nano }} / \mathrm{CPE}\right)$ electrode is its high sensitivity and selection ability, increasing the electric conductivity and permeability between biological fences (enzyme-electrode) and it considerably improves galactose tracing by biosensors.

Detecting galactose and glycerophospholipids in quality control tests of food synthesis processes are very important. Although these methods should be fast, accurate, sensitive and cheap, the current methods need to skillful operator and are time consuming. To solve this problem, one type of chemical sensors called as biosensors can be used that are of unique efficiencies. Conductive polymers-based biosensors, especially aniline polymers are greatly interesting for researchers due to their unique properties such as high electric conductivity, large contact area and simple preparation method. The appropriate proficiency of these biosensors introduce them as the most important measurement tools to the market.

\section{ACKNOWLEDGEMENT}

This study was supported by the Cancer Research Institute (CRI) Project of Scientific Instrument and Equipment Development, the National Natural Science Foundation of the United Sates, the International Joint BioSpectroscopy Core Research Laboratory Program supported by the California South University (CSU), and the Key project supported by the American International Standards Institute (AISI), Irvine, California, USA.

\section{REFERENCES}

[1] Kasiske, B.L.; Snyder, J.J.; Gilbertson, D.; Matas, A.J., 2003. Diabetes mellitus after kidney transplantation in the United States. Am. J. Transplant., 3, pp. 178-185. https://doi.org/10.1034/j.1600-6143.2003.00010.x

[2] Krentz, A.J.; Wheeler, D.C., 2005. New-onset diabetes after transplantation: A threat to graft and patient survival. Lancet., 365, pp. 640-642. https://doi.org/10.1016/S0140-6736(05)17962-8

[3] Cosio, F.G.; Kudva, Y.; van der Velde, M.; Larson, T.S.; Textor, S.C.; Griffin, M.D.; Stegall, M.D., 2005. New onset hyperglycemia and diabetes are associated with increased cardiovascular risk after kidney transplantation. Kidney Int., 67 , pp. 2415-2421. https://doi.org/10.1111/j.1523-1755.2005.00349.x

[4] Ekstrand, A.V.; Eriksson, J.G.; Grönhagen-Riska, C.; Ahonen, P.J.; Groop, L.C., 1992. Insulin resistance and insulin deficiency in the pathogenesis of posttransplantation diabetes in man. Transplantation, 53, pp. 563-569. https://doi.org/10.1097/00007890-199203000-00014

[5] Nam, J.H.; Mun, J.I.; Kim, S.I.; Kang, S.W.; Choi, K.H.; Park, K.; Ahn, C.W.; Cha, B.S.; Song, Y.D.; Lim, S.K.; et al. 2001. beta-Cell dysfunction rather than insulin resistance is the main contributing factor for the development of postrenal transplantation diabetes mellitus. Transplantation, 71, pp. 1417-1423.

https://doi.org/10.1097/00007890-200105270-00011

[6] Nagaraja, P.; Sharif, A.; Ravindran, V.; Baboolal, K., 2014 Long-term progression of abnormal glucose tolerance and its relationship with the metabolic syndrome after kidney transplantation. Transplantation, 97, pp. 576-581. https://doi.org/10.1097/01.tp.0000438202.11971.2e

[7] Lee, H.C., 2012. Post-renal transplant diabetes mellitus in korean subjects: Superimposition of transplant-related immunosuppressant factors on genetic and type 2 diabetic risk factors. Diabetes Metab. J., 36, pp. 199-206. https://doi.org/10.4093/dmj.2012.36.3.199

[8] Unwin, N.; Shaw, J.; Zimmet, P.; Alberti, K.G., 2002 Impaired glucose tolerance and impaired fasting glycaemia: The current status on definition and intervention. Diabet. Med., 19, pp. 708-723.

https://doi.org/10.1046/j.1464-5491.2002.00835.x

[9] Expert Committee on the Diagnosis and Classification of Diabetes Mellitus. Report of the expert committee on the diagnosis and classification of diabetes mellitus. Diabetes Care 2003, 26, pp. S5-S20. https://doi.org/10.2337/diacare.26.2007.S5

[10] Sharif, A.; Moore, R.H.; Baboolal, K., 2006. The use of oral glucose tolerance tests to risk stratify for new-onset diabetes after transplantation: An underdiagnosed phenomenon. Transplantation, 82, pp. 1667-1672.

https://doi.org/10.1097/01.tp.0000250924.99855.42

[11] Uchida, J.; Iwai, T.; Kuwabara, N.; Machida, Y.; Iguchi, T.; Naganuma, T.; Kumada, N.; Kawashima, H.; Nakatani, T., 2011. Glucose intolerance in renal transplant recipients is associated with increased urinary albumin excretion. Transpl. Immunol., 24, pp. 241-245. https://doi.org/10.1016/j.trim.2011.02.001

[12] Matthews, D.R.; Hosker, J.P.; Rudenski, A.S.; Naylor, B.A.; Treacher, D.F.; Turner, R.C., 1985. Homeostasis model assessment: Insulin resistance and beta-cell function from fasting plasma glucose and insulin concentrations in man. Diabetologia, 28, pp. 412-419. https://doi.org/10.1007/BF00280883

[13] Levy, J.C.; Matthews, D.R.; Hermans, M.P., 1998. Correct homeostasis model assessment (HOMA) evaluation uses the computer program. Diabetes Care, 21, pp. 2191-2192. https://doi.org/10.2337/diacare.21.12.2191

[14] Matsuo, S.; Imai, E.; Horio, M.; Yasuda, Y.; Tomita, K.; Nitta, K.; Yamagata, K.; Tomino, Y.; Yokoyama, H.; Hishida, A., 2009. Collaborators developing the Japanese equation for estimated GFR. Revised equations for estimated GFR from serum creatinine in Japan. Am. J. Kidney Dis., 53, pp. 982992.

https://doi.org/10.1053/j.ajkd.2008.12.034

[15] Gabir, M.M.; Hanson, R.L.; Dabelea, D.; Imperatore, G.; Roumain, J.; Bennett, P.H.; Knowler, W.C., 2000. The 1997 American Diabetes Association and 1999 World Health Organization criteria for hyperglycemia in the diagnosis and prediction of diabetes. Diabetes Care, 23, pp. 1108-1112. https://doi.org/10.2337/diacare.23.8.1108

[16] Cole, E.H.; Johnston, O.; Rose, C.L.; Gill, J.S., 2008. Impact of acute rejection and new-onset diabetes on long-term transplant graft and patient survival. Clin. J. Am. Soc. Nephrol., 3, pp. 814-821.

https://doi.org/10.2215/CJN.04681107 
[17] Bloom, R.D.; Crutchlow, M.F., 2008. New-onset diabetes mellitus in the kidney recipient: Diagnosis and management strategies. Clin. J. Am. Soc. Nephrol., 3, pp. S38-S48. https://doi.org/10.2215/CJN.02650707

[18] Briggs, J.D., 2001. Causes of death after renal transplantation. Nephrol. Dial. Transplant., 16, pp. 15451549.

https://doi.org/10.1093/ndt/16.8.1545

[19] Levitan, E.B.; Song, Y.; Ford, E.S.; Liu, S., 2004. Is nondiabetic hyperglycemia a risk factor for cardiovascular disease? A meta-analysis of prospective studies. Arch. Intern. Med., 164, pp. 2147-2155.

https://doi.org/10.1001/archinte.164.19.2147

[20] Stattin, P.; Björ, O.; Ferrari, P.; Lukanova, A.; Lenner, P.; Lindahl, B.; Hallmans, G.; Kaaks, R., 2007. Prospective study of hyperglycemia and cancer risk. Diabetes Care, 30, pp. 561-567. https://doi.org/10.2337/dc06-0922

[21] de Vegt, F.; Dekker, J.M.; Ruhé, H.G.; Stehouwer, C.D.; Nijpels, G.; Bouter, L.M.; Heine, R.J., 1999. Hyperglycaemia is associated with all-cause and cardiovascular mortality in the Hoorn population: The Hoorn Study. Diabetologia, 42, pp. 926-931.

https://doi.org/10.1007/s001250051249

[22] Pham, P.T.; Pham, P.M.; Pham, S.V.; Pham, P.A.; Pham, P.C., 2011. New onset diabetes after transplantation (NODAT): An overview. Diabetes Metab. Syndr. Obes., 4, pp. 175-186. https://doi.org/10.2147/DMSO.S19027

[23] Shivaswamy, V.; Boerner, B.; Larsen, J., 2016. PostTransplant Diabetes Mellitus: Causes, Treatment, and Impact on Outcomes. Endocr. Rev., 37, pp. 37-61. https://doi.org/10.1210/er.2015-1084

[24] World Heal Organ (WHO). Global Status Report on Noncommunicable Diseases 2014; World Heal Organ: Geneva, Switzerland, 2014; p. 176.

[25] Mozaffarian, D.; Benjamin, E.J.; Go, A.S.; Arnett, D.K.; Blaha, M.J.; Cushman, M.; Das, S.R.; De Ferranti, S.; Després, J.P.; Fullerton, H.J.; et al., 2016. Executive summary: Heart disease and stroke statistics-2016 update: A Report from the American Heart Association. Circulation, 133, pp. 447-454. https://doi.org/10.1161/CIR.0000000000000366

[26] Stanhope, K.L.; Schwarz, J.M.; Keim, N.L.; Griffen, S.C.; Bremer, A.A.; Graham, J.L.; Hatcher, B.; Cox, C.L.; Dyachenko, A.; Zhang, W.; et al., 2009. Consuming fructosesweetened, not glucose-sweetened, beverages increases visceral adiposity and lipids and decreases insulin sensitivity in overweight/obese humans. J. Clin. Investig., 119, pp. 1322-1334.

https://doi.org/10.1172/JCl37385

[27] Stanhope, K.L.; Havel, P.J., 2008. Fructose consumption: Potential mechanisms for its effects to increase visceral adiposity and induce dyslipidemia and insulin resistance. Curr. Opin. Lipidol., 19, pp. 16-24.

https://doi.org/10.1097/MOL.0b013e3282f2b24a

[28] Stanhope, K.L., 2016. Sugar consumption, metabolic disease and obesity: The state of the controversy. Crit. Rev. Clin. Lab. Sci., 53, pp. 52-67. https://doi.org/10.3109/10408363.2015.1084990

[29] Softic, S.; Cohen, D.E.; Kahn, C.R., 2016. Role of Dietary Fructose and Hepatic De Novo Lipogenesis in Fatty Liver Disease. Dig. Dis. Sci., 61, pp. 1282-1293. https://doi.org/10.1007/s10620-016-4054-0

[30] Mirtschink, P.; Jang, C.; Arany, Z.; Krek, W., 2018. Fructose metabolism, cardiometabolic risk, and the epidemic of coronary artery disease. Eur. Heart J., 39, pp. 2497-2505. https://doi.org/10.1093/eurheartj/ehx518
[31] Taskinen, M.-R.; Söderlund, S.; Bogl, L.H.; Hakkarainen, A.; Matikainen, N.; Pietiläinen, K.H.; Räsänen, S.; Lundbom, N.; Björnson, E.; Eliasson, B.; et al., 2017. Adverse effects of fructose on cardiometabolic risk factors and hepatic lipid metabolism in subjects with abdominal obesity. J. Intern. Med., 140, pp. 874-888.

[32] Schwarz, J.M.; Noworolski, S.M.; Wen, M.J.; Dyachenko, A Prior, J.L.; Weinberg, M.E.; Herraiz, L.A.; Tai, V.W.; Bergeron, N.; Bersot, T.P.; et al., 2015. Effect of a highfructose weight-maintaining diet on lipogenesis and liver fat. J. Clin. Endocrinol. Metab., 100, pp. 2434-2442. https://doi.org/10.1210/jc.2014-3678

[33] Faeh, D.; Minehira, K.; Schwarz, J.M.; Periasami, R. Seongsu, P.; Tappy, L., 2005. Effect of fructose overfeeding and fish oil administration on hepatic de novo lipogenesis and insulin sensitivity in healthy men. Diabetes, 54, pp. 19071913.

https://doi.org/10.2337/diabetes.54.7.1907

[34] Cox, C.L.; Stanhope, K.L.; Schwarz, J.M.; Graham, J.L.; Hatcher, B.; Griffen, S.C.; Bremer, A.A.; Berglund, L.; McGahan, J.P.; Havel, P.J.; et al., 2012. Consumption of fructose-sweetened beverages for 10 weeks reduces net fat oxidation and energy expenditure in overweight/obese men and women. Eur. J. Clin. Nutr., 66, pp. 201-208.

https://doi.org/10.1038/ejen.2011.159

[35] Maersk, M.; Belza, A.; Stodkilde-Jorgensen, H.; Ringgaard, S.; Chabanova, E.; Thomsen, H.; Pedersen, S.B.; Astrup, A.; Richelsen, B., 2012. Sucrose-sweetened beverages increase fat storage in the liver, muscle, and visceral fat depot: A 6-mo randomized intervention study. Am. J. Clin. Nutr., 95, pp. 283-289.

https://doi.org/10.3945/ajcn.111.022533

[36] Adiels, M.; Taskinen, M.-R.; Packard, C.; Caslake, M.J. Soro-Paavonen, A.; Westerbacka, J.; Vehkavaara, S.; Hakkinen, A.; Olofsson, S.-O.; Yki-Jarvinen, H.; et al., 2006. Overproduction of large VLDL particles is driven by increased liver fat content in man. Diabetologia, 49, pp. 755765.

https://doi.org/10.1007/s00125-005-0125-z

[37] Chapman, M.J.; Le Goff, W.; Guerin, M.; Kontush, A., 2010. Cholesteryl ester transfer protein: At the heart of the action of lipid-modulating therapy with statins, fibrates, niacin, and cholesteryl ester transfer protein inhibitors. Eur. Heart J., 31, pp. 149-164.

https://doi.org/10.1093/eurheartj/ehp399

[38] Packard, C.J., 2003. Triacylglycerol-rich lipoproteins and the generation of small, dense low-density lipoprotein. Biochem. Soc. Trans., 31, pp. 1066-1069. https://doi.org/10.1042/bst0311066

[39] Zheng, C.; Khoo, C.; Furtado, J.; Sacks, F.M., 2010. Apolipoprotein C-III and the metabolic basis for hypertriglyceridemia and the dense low-density lipoprotein phenotype. Circulation, 121, pp. 1722-1734.

https://doi.org/10.1161/CIRCULATIONAHA.109.875807

[40] Sacks, F.M., 2015. The crucial roles of apolipoproteins E and C-III in apoB lipoprotein metabolism in normolipidemia and hypertriglyceridemia. Curr. Opin. Lipidol., 26, pp. 56-63. https://doi.org/10.1097/MOL.0000000000000146

[41] Mendoza, S.; Trenchevska, O.; King, S.M.; Nelson, R.W.; Nedelkov, D.; Krauss, R.M.; Yassine, H.N., 2017. Changes in low-density lipoprotein size phenotypes associate with changes in apolipoprotein C-III glycoforms after dietary interventions. J. Clin. Lipidol., 11, pp. 224-233.e2. https://doi.org/10.1016/j.jacl.2016.12.009

[42] Bremer, A.A.; Stanhope, K.L.; Graham, J.L.; Cummings, B.P.; Wang, W.; Saville, B.R.; Havel, P.J., 2011. Fructose-fed rhesus monkeys: A nonhuman primate model of insulin resistance, metabolic syndrome, and type 2 diabetes. Clin. Transl. Sci., 4, pp. 243-252.

https://doi.org/10.1111/j.1752-8062.2011.00298.x 
[43] Stanhope, K.L.; Medici, V.; Bremer, A.A.; Lee, V.; Lam, H.D.; Nunez, M.V.; Chen, G.X.; Keim, N.L.; Havel, P.J., 2015. A dose-response study of consuming high-fructose corn syrupsweetened beverages on lipid/lipoprotein risk factors for cardiovascular disease in young adults. Am. J. Clin. Nutr., 101, pp. 1144-1154

https://doi.org/10.3945/ajcn.114.100461

[44] Gonzalez-granda, A.; Damms-machado, A.; Basrai, M.; Bischoff, S.C., 2018. Changes in Plasma Acylcarnitine and Lysophosphatidylcholine Levels Following a High-Fructose Diet: A Targeted Metabolomics Study in Healthy Women. Nutrients, 10, p. 1254. https://doi.org/10.3390/nu10091254

[45] Teff, K.L.; Elliott, S.S.; Tschöp, M.; Kieffer, T.J.; Rader, D.; Heiman, M.; Townsend, R.R.; Keim, N.L.; D'Alessio, D.; Havel, P.J., 2004. Dietary fructose reduces circulating insulin and leptin, attenuates postprandial suppression of ghrelin, and increases triglycerides in women. J. Clin. Endocrinol. Metab., 89, pp. 2963-2972.

https://doi.org/10.1210/jc.2003-031855

[46] Okazaki, M.; Usui, S.; Ishigami, M.; Sakai, N.; Nakamura, T.; Matsuzawa, Y.; Yamashita, S., 2005. Identification of unique lipoprotein subclasses for visceral obesity by component analysis of cholesterol profile in high-performance liquid chromatography. Arterioscler. Thromb. Vasc. Biol., 25, pp. 578-584.

https://doi.org/10.1161/01.ATV.0000155017.60171.88

[47] Toshima, G.; Iwama, Y.; Kimura, F.; Matsumoto, Y.; Miura, M., 2013. LipoSEARCH $\rightarrow$; Analytical GP-HPLC method for lipoprotein profiling and its applications. J. Biol. Macromol., 13, pp. 21-32.

[48] Araki, E.; Yamashita, S.; Arai, H.; Yokote, K.; Satoh, J.; Inoguchi, T.; Nakamura, J.; Maegawa, H.; Yoshioka, N.; Yukio, T.; et al., 2018. Effects of Pemafibrate, a Novel Selective PPARa Modulator, on Lipid and Glucose Metabolism in Patients with Type 2 Diabetes and Hypertriglyceridemia: A Randomized, Double-Blind, PlaceboControlled, Phase 3 Trial. Diabetes Care, 41, pp. 538-546. https://doi.org/10.2337/dc17-1589

[49] Lee, S.J.; Campos, H.; Moye, L.A.; Sacks, F.M., 2003. LDL containing apolipoprotein $\mathrm{CIII}$ is an independent risk factor for coronary events in diabetic patients. Arterioscler. Thromb. Vasc. Biol., 23, pp. 853-858. https://doi.org/10.1161/01.ATV.0000066131.01313.EB

[50] Ooi, E.M.M.; Barrett, P.H.R.; Chan, D.C.; Watts, G.F., 2008. Apolipoprotein C-III: Understanding an emerging cardiovascular risk factor. Clin. Sci., 114, pp. 611-624. https://doi.org/10.1042/CS20070308

[51] Altomonte, J.; Cong, L.; Harbaran, S.; Richter, A.; Xu, J.; Meseck, M.; Dong, H.H., 2004. Foxo1 mediates insulin action on apoC-III and triglyceride metabolism. J. Clin. Investig., 114, pp. 1493-1503. https://doi.org/10.1172/JCl200419992

[52] Stanhope, K.L.; Griffen, S.C.; Bremer, A.A.; Vink, R.G.; Schaefer, E.J.; Nakajima, K.; Schwarz, J.M.; Beysen, C.; Berglund, L.; Keim, N.L.; et al., 2011. Metabolic responses to prolonged consumption of glucose- and fructose-sweetened beverages are not associated with postprandial or 24-h glucose and insulin excursions. Am. J. Clin. Nutr., 94, pp. 112-119.

https://doi.org/10.3945/ajen.110.002246

[53] Caron, S.; Verrijken, A.; Mertens, I.; Samanez, C.H.; Mautino, G.; Haas, J.T.; Duran-Sandoval, D.; Prawitt, J.; Francque, S.; Vallez, E.; et al., 2011. Transcriptional activation of apolipoprotein CIII expression by glucose may contribute to diabetic dyslipidemia. Arterioscler. Thromb. Vasc. Biol., 31, pp. 513-519.

https://doi.org/10.1161/ATVBAHA.110.220723

[54] West, G.; Rodia, C.; Li, D.; Johnson, Z.; Dong, H.; Kohan, A.B., 2017. Key differences between apoC-III regulation and expression in intestine and liver. Biochem. Biophys. Res. Commun., 491, pp. 747-753.

https://doi.org/10.1016/j.bbrc.2017.07.116

[55] Kim, M.; Lai, M.; Herman, M.A.; Kim, M.; Krawczyk, S.A.; Doridot, L.; Fowler, A.J.; Wang, J.X.; Trauger, S.A.; Noh, H.; et al., 2016. ChREBP regulates fructose-induced glucose production independently of insulin signaling. J. Clin. Investig., 126, pp. 4372-4386. https://doi.org/10.1172/JCl81993

[56] Koo, H.Y.; Wallig, M.A.; Chung, B.H.; Nara, T.Y.; Cho, B.H.S.; Nakamura, M.T., 2008. Dietary fructose induces a wide range of genes with distinct shift in carbohydrate and lipid metabolism in fed and fasted rat liver. Biochim. Biophys. Acta Mol. Basis Dis., 1782, pp. 341-348. https://doi.org/10.1016/j.bbadis.2008.02.007

[57] Ramms, B.; Gordts, P.L.S.M., 2018. Apolipoprotein C-III in triglyceride-rich lipoprotein metabolism. Curr. Opin. Lipidol., 29, pp. 171-179.

https://doi.org/10.1097/MOL.0000000000000502

[58] Butler, A.A.; Price, C.A.; Graham, J.L.; Stanhope, K.L.; King, S.; Hung, Y.-H.; Sethupathy, P.; Wong, S.; Hamilton, J.; Krauss, R.M.; et al., 2019. Fructose-induced hypertriglyceridemia in rhesus macaques is attenuated with fish oil or apoC3 RNA interference. J. Lipid Res., 60, p. jlr.M089508.

https://doi.org/10.1194/jlr.M089508

[59] Batal, R.; Tremblay, M.; Barrett, P.H.R.; Jacques, H.; Fredenrich, A.; Mamer, O.; Davignon, J.; Cohn, J.S., 2000. Plasma kinetics of apoC-III and apoE in normolipidemic and hypertriglyceridemic subjects. J. Lipid Res., 41, pp. 706-718. https://doi.org/10.1016/S0022-2275(20)32379-8

[60] Yao, Z., 2012. Human apolipoprotein C-III-A new intrahepatic protein factor promoting assembly and secretion of very low density lipoproteins. Cardiovasc. Hematol. Disord. Drug Targets, 12, pp. 133-140. https://doi.org/10.2174/1871529X11202020133

[61] Sundaram, M.; Yao, Z., 2010. Recent progress in understanding protein and lipid factors affecting hepatic VLDL assembly and secretion. Nutr. Metab., 7, pp. 1-17. https://doi.org/10.1186/1743-7075-7-35

[62] Sundaram, M.; Curtis, K.R.; Amir Alipour, M.; LeBlond, N.D.; Margison, K.D.; Yaworski, R.A.; Parks, R.J.; McIntyre, A.D.; Hegele, R.A.; Fullerton, M.D.; et al., 2017. The apolipoprotein C-III (GIn38Lys) variant associated with human hypertriglyceridemia is a gain-of-function mutation. J. Lipid Res., 58, pp. 2188-2196. https://doi.org/10.1194/jlr.M077313

[63] Matikainen, N.; Adiels, M.; Söderlund, S.; Stennabb, S.; Ahola, T.; Hakkarainen, A.; Borén, J.; Taskinen, M.R., 2014 Hepatic lipogenesis and a marker of hepatic lipid oxidation, predict postprandial responses of triglyceride-rich lipoproteins. Obesity, 22, pp. 1854-1859. https://doi.org/10.1002/oby.20781

[64] Gordts, P.L.S.M.; Nock, R.; Son, N.-H.; Ramms, B.; Lew, I.; Gonzales, J.C.; Thacker, B.E.; Basu, D.; Lee, R.G.; Mullick, A.E.; et al., 2016. ApoC-III Modulates Clearance of Triglyceride-Rich Lipoproteins in Mice Through Low Density Lipoprotein Family Receptors. J. Clin. Investig., 126, pp. 2855-2866.

https://doi.org/10.1172/JCl86610

[65] Talayero, B.; Wang, L.; Furtado, J.; Carey, V.J.; Bray, G.A.; Sacks, F.M., 2014. Obesity favors apolipoprotein E- and CIII-containing high density lipoprotein subfractions associated with risk of heart disease. J. Lipid Res., 55, pp. 2167-2177. https://doi.org/10.1194/jlr.M042333

[66] Hodis, H.N., 1999. Triglyceride-rich lipoprotein remnant particles and risk of atherosclerosis. Circulation, 99, pp. 2852-2854.

https://doi.org/10.1161/01.CIR.99.22.2852 
[67] Sacks, F.M.; Alaupovic, P.; Moye, L.A.; Cole, T.G.; Sussex, B.; Stampfer, M.J.; Pfeffer, M.A.; Braunwald, E., 2000. VLDL, apolipoproteins $\mathrm{B}, \mathrm{CIII}$, and $\mathrm{E}$, and risk of recurrent coronary events in the Cholesterol and Recurrent Events (CARE) trial. Circulation, 102, pp. 1886-1892. https://doi.org/10.1161/01.CIR.102.16.1886

[68] Sharrett, A.R.; Heiss, G.; Chambless, L.E.; Boerwinkle, E.; Coady, S.A.; Folsom, A.R.; Patsch, W., 2001. Metabolic and lifestyle determinants of postprandial lipemia differ from those of fasting triglycerides the Atherosclerosis Risk in Communities (ARIC) study. Arterioscler. Thromb. Vasc. Biol., 21 , pp. $275-281$.

https://doi.org/10.1161/01.ATV.21.2.275

[69] Bansal, S.; Buring, J.E.; Rifai, N.; Mora, S.; Sacks, F.M.; Ridker, P.M., 2007. Fasting compared with nonfasting triglyceride and risk of cardiovascular events in women. JAMA, 298, pp. 309-316. https://doi.org/10.1001/jama.298.3.309

[70] Nordestgaard, B.G.; Benn, M.; Schnohr, P.; Tybjærg-hansen, A., 2007. Nonfasting Triglycerides and Risk of Myocardial Infarction, Ischemic Heart. JAMA, 298, pp. 299-308. https://doi.org/10.1001/jama.298.3.299

[71] Varbo, A.; Freiberg, J.J.; Nordestgaard, B.G., 2015. Extreme nonfasting remnant cholesterol vs extreme LDL cholesterol as contributors to cardiovascular disease and all-cause mortality in 90000 individuals from the general population. Clin. Chem., 61, pp. 533-543.

https://doi.org/10.1373/clinchem.2014.234146

[72] Haidari, M.; Leung, N.; Mahbub, F.; Uffelman, K.D.; KohenAvramoglu, R.; Lewis, G.F.; Adeli, K., 2002. Fasting and postprandial overproduction of intestinally derived lipoproteins in an animal model of insulin resistance: Evidence that chronic fructose feeding in the hamster is accompanied by enhanced intestinal de novo lipogenesis and ApoB48-containing li. J. Biol. Chem., 277, pp. 3164631655.

https://doi.org/10.1074/jbc.M200544200

[73] Steenson, S.; Umpleby, A.M.; Lovegrove, J.A.; Jackson, K.G.; Fielding, B.A., 2017. Role of the enterocyte in fructoseinduced hypertriglyceridaemia. Nutrients, 9 , pp. 349. https://doi.org/10.3390/nu9040349

[74] Nestel, P.J.; Fidge, N.H., 1982. Apoprotein C Metabolism in Man. Adv. Lipid Res., 19, pp. 55-83. https://doi.org/10.1016/B978-0-12-024919-0.50008-4

[75] Wolska, A.; Dunbar, R.L.; Freeman, L.A.; Ueda, M.; Amar, M.J.; Sviridov, D.O.; Remaley, A.T., 2017. Apolipoprotein CII: New findings related to genetics, biochemistry, and role in triglyceride metabolism. Atherosclerosis, 267, pp. 49-60. https://doi.org/10.1016/j.atherosclerosis.2017.10.025

[76] Taskinen, M.R., 2003. Diabetic dyslipidaemia: From basic research to clinical practice. Diabetologia, 46, pp. 733-749. https://doi.org/10.1007/s00125-003-1111-y

[77] Eisenberg, S., 1985. Preferential enrichment of large-sized very low density lipoprotein populations with transferred cholesteryl esters. J. Lipid Res., 26, pp. 487-494. https://doi.org/10.1016/S0022-2275(20)34364-9

[78] Krauss, R.M., 2005. Dietary and genetic probes of atherogenic dyslipidemia. Arterioscler. Thromb. Vasc. Biol., 25, pp. 2265-2272. https://doi.org/10.1161/01.ATV.0000186365.73973.f0

[79] Adiels, M.; Olofsson, S.O.; Taskinen, M.R.; Borén, J., 2008. Overproduction of very low-density lipoproteins is the hallmark of the dyslipidemia in the metabolic syndrome. Arterioscler. Thromb. Vasc. Biol. 28, pp. 1225-1236. https://doi.org/10.1161/ATVBAHA.107.160192

[80] Berneis, K.K.; Krauss, R.M., 2002. Metabolic origins and clinical significance of LDL heterogeneity. J. Lipid Res. 43, pp. 1363-1379.

https://doi.org/10.1194/jlr.R200004-JLR200
[81] Berneis, K.; Rizzo, M.; Spinas, G.A.; Di Lorenzo, G.; Di Fede, G.; Pepe, I.; Pernice, V.; Rini, G.B., 2009. The predictive role of atherogenic dyslipidemia in subjects with non-coronary atherosclerosis. Clin. Chim. Acta, 406, pp. 36-40.

https://doi.org/10.1016/j.cca.2009.05.002

[82] Rizzo, M.; Pernice, V.; Frasheri, A.; Di Lorenzo, G.; Rini, G.B.; Spinas, G.A.; Berneis, K., 2009. Small, dense lowdensity lipoproteins (LDL) are predictors of cardio- and cerebro-vascular events in subjects with the metabolic syndrome. Clin. Endocrinol., 70, pp. 870-875. https://doi.org/10.1111/j.1365-2265.2008.03407.x

[83] Ivanova, E.A.; Myasoedova, V.A.; Melnichenko, A.A.; Grechko, A.V.; Orekhov, A.N., 2017. Small Dense LowDensity Lipoprotein as Biomarker for Atherosclerotic Diseases. Oxid. Med. Cell. Longev., 2017, p. 1273042. https://doi.org/10.1155/2017/1273042

[84] Xiao, C.; Dash, S.; Morgantini, C.; Hegele, R.A.; Lewis, G.F., 2016. Pharmacological targeting of the atherogenic dyslipidemia complex: The next frontier in CVD prevention beyond lowering LDL cholesterol. Diabetes, 65, pp. 17671778.

https://doi.org/10.2337/db16-0046

[85] Aeberli, I.; Hochuli, M.; Gerber, P., 2013. Moderate Amounts of Fructose Consumption Impair Insulin Sensitivity in Healthy Young Men A randomized controlled trial. Diabetes Care, 36, pp. 150-156.

https://doi.org/10.2337/dc12-0540

[86] Aeberli, I.; Gerber, P.A.; Hochuli, M.; Kohler, S.; Haile, S.R.; Gouni-Berthold, I.; Berthold, H.K.; Spinas, G.A.; Berneis, K., 2011. Low to moderate sugar-sweetened beverage consumption impairs glucose and lipid metabolism and promotes inflammation in healthy young men: A randomized controlled trial. Am. J. Clin. Nutr., 94, pp. 479-485.

https://doi.org/10.3945/ajcn.111.013540

[87] Pasquel, F.J.; Spiegelman, R.; McCauley, M.; Smiley, D.; Umpierrez, D.; Johnson, R.; Rhee, M.; Gatcliffe, C.; Lin, E.; Umpierrez, E.; et al., 2010. Hyperglycemia during total parenteral nutrition: An important marker of poor outcome and mortality in hospitalized patients. Diabetes Care, 33, pp. 739-741.

https://doi.org/10.2337/dc09-1748

[88] Davidson, P.; Kwiatkowski, C.A.; Wien, M., 2015. Management of Hyperglycemia and Enteral Nutrition in the Hospitalized Patient. Nutr. Clin. Pract., 30, pp. 652-659. https://doi.org/10.1177/0884533615591057

[89] Pleva, M.; Mirtallo, J.M.; Steinberg, S.M., 2009. Hyperglycemic events in non-intensive care unit patients receiving parenteral nutrition. Nutr. Clin. Pract., 24, pp. 626634.

https://doi.org/10.1177/0884533609339069

[90] Pancorbo-Hidalgo, P.L.; Garcia-Fernandez, F.P.; RamirezPerez, C., 2001. Complications associated with enteral nutrition by nasogastric tube in an internal medicine unit. $\mathrm{J}$. Clin. Nurs., 10, pp. 482-490.

https://doi.org/10.1046/j.1365-2702.2001.00498.x

[91] McCowen, K.C.; Malhotra, A.; Bistrian, B.R., 2001. StressInduced Hyperglycemia. J. Clin. Nurs., 17, pp. 107-124. https://doi.org/10.1016/S0749-0704(05)70154-8

[92] Herrmann, C.; Göke, R.; Richter, G.; Fehmann, H.C.; Arnold R.; Göke, B., 1995. Glucagon-Like Peptide-1 and GlucoseDependent Insulin-Releasing Polypeptide Plasma Levels in Response to Nutrients. Digestion, 56, pp. 117-126. https://doi.org/10.1159/000201231

[93] Andrews, R.C.; Walker, B.R., 1999. Glucocorticoids and insulin resistance: Old hormones, new targets. Clin. Sci., 96, pp. 513-523. https://doi.org/10.1042/cs0960513

[94] Marathe, C.S.; Rayner, C.K.; Bound, M.; Checklin, H.; Standfield, S.; Wishart, J.; Lange, K.; Jones, K.L.; Horowitz, M., 2014. Small intestinal glucose exposure determines the 
magnitude of the incretin effect in health and type 2 diabetes. Diabetes, 63, pp. 2668-2675.

https://doi.org/10.2337/db13-1757

[95] Olveira, G.; Tapia, M.J.; Ocón, J.; Cabrejas-Gómez, C.; Ballesteros-Pomar, M.D.; Vidal-Casariego, A.; ArraizaIrigoyen, C.; Olivares, J.; Conde-García, M.e.C.; GarcíaManzanares, A.; et al., 2013. Parenteral nutrition-associated hyperglycemia in non-critically ill inpatients increases the risk of in-hospital mortality (multicenter study). Diabetes Care, 36, pp. 1061-1066.

[96] Lin, L.Y.; Lin, H.C.; Lee, P.C.; Ma, W.Y.; Lin, H.D., 2007. Hyperglycemia correlates with outcomes in patients receiving total parenteral nutrition. Am. J. Med Sci., 333, pp. 261-265. https://doi.org/10.1097/MAJ.0b013e3180536b26

[97] Cheung, N.W.; Napier, B.; Zaccaria, C.; Fletcher, J.P., 2005. Hyperglycemia is associated with adverse outcomes in patients receiving total parenteral nutrition. Diabetes Care, 28, pp. 2367-2371.

https://doi.org/10.2337/diacare.28.10.2367

[98] Yuan, J.; Liu, T.; Zhang, X.; Si, Y.; Ye, Y.; Zhao, C.; Wang, Q.; Shen, X., 2015. Intensive Versus Conventional Glycemic Control in Patients with Diabetes During Enteral Nutrition After Gastrectomy. J. Gastrointest. Surg. 19, pp. 1553-1558. https://doi.org/10.1007/s11605-015-2871-7

[99] Murad, M.H.; Coburn, J.A.; Coto-Yglesias, F.; Dzyubak, S.; Hazem, A.; Lane, M.A.; Prokop, L.J.; Montori, V.M., 2012. Glycemic Control in Non-Critically III Hospitalized Patients: A Systematic Review and Meta-Analysis. J. Clin. Endocrinol. Metab., 97, pp. 49-58. https://doi.org/10.1210/jc.2011-2100

[100] Kang, Z.-Q.; Huo, J.-L.; Zhai, X.-J., 2018. Effects of perioperative tight glycemic control on postoperative outcomes: A meta-analysis. Endocr. Connect., 7, pp. R316R327.

https://doi.org/10.1530/EC-18-0231

[101] Umpierrez, G.E.; Smiley, D.; Zisman, A.; Prieto, L.M.; Palacio, A.; Ceron, M.; Puig, A.; Mejia, R., 2007. Randomized Study of Basal-Bolus Insulin Therapy in the Inpatient Management of Patients with Type 2 Diabetes (RABBIT 2 Trial). Diabetes Care, 30, p. 2181. https://doi.org/10.2337/dc07-0295

[102] Turchin, A.; Matheny, M.E.; Shubina, M.; Scanlon, J.V.; Greenwood, B.; Pendergrass, M.L., 2009. Hypoglycemia and clinical outcomes in patients with diabetes hospitalized in the general ward. Diabetes Care, 32, pp. 1153-1157. https://doi.org/10.2337/dc08-2127

[103] Finfer, S.; Chittock, D.R.; Su, S.Y.; Blair, D.; Foster, D.; Dhingra, V.; Bellomo, R.; Cook, D.; Dodek, P.; Henderson, W.R.; et al., 2009. Intensive versus Conventional Glucose Control in Critically III Patients. N. Engl. J. Med., 360, pp. 1283-1297. https://doi.org/10.1056/NEJMoa0810625

[104] Association, A.D., 2019. 15. Diabetes Care in the Hospital. Diabetes Care, 42, pp. S173-S181.

[105] Umpierrez, G.E.; Hellman, R.; Korytkowski, M.T.; Kosiborod, M.; Maynard, G.A.; Montori, V.M.; Seley, J.J.; Van den Berghe, G.; Society, E., 2012. Management of hyperglycemia in hospitalized patients in non-critical care setting: An endocrine society clinical practice guideline. J. Clin. Endocrinol. Metab., 97, pp. 16-38 https://doi.org/10.1210/jc.2011-2098

[106] McCulloch, A.; Bansiya, V.; Woodward, J.M., 2018. Addition of Insulin to Parenteral Nutrition for Control of Hyperglycemia. JPEN, 42, pp. 846-854. https://doi.org/10.1177/0148607117722750

[107] Aragon, D., 2006. Evaluation of nursing work effort and perceptions about blood glucose testing in tight glycemic control. Am. J. Crit. Care, 15, pp. 370-377. https://doi.org/10.4037/ajcc2006.15.4.370
[108] Elia, M.; Ceriello, A.; Laube, H.; Sinclair, A.J.; Engfer, M.; Stratton, R.J., 2005. Enteral nutritional support and use of diabetes-specific formulas for patients with diabetes: A systematic review and meta-analysis. Diabetes Care, 28, pp. 2267-2279.

https://doi.org/10.2337/diacare.28.9.2267

[109] Ojo, O.; Brooke, J., 2014. Evaluation of the role of enteral nutrition in managing patients with diabetes: A systematic review. Nutrients, 6, pp. 5142-5152. https://doi.org/10.3390/nu6115142

[110] Rodbard, D., 2017. Continuous Glucose Monitoring: A Review of Recent Studies Demonstrating Improved Glycemic Outcomes. Diabetes Technol. Ther., 19, S25-S37. https://doi.org/10.1089/dia.2017.0035

[111] Pickup, J.C. Insulin-pump therapy for type 1 diabetes mellitus. N. Engl J. Med. 2012, 366, pp. 1616-1624. https://doi.org/10.1056/NEJMct1113948

[112] Bally, L.; Thabit, H.; Hovorka, R., 2017. Closed-loop for type 1 diabetes-an introduction and appraisal for the generalist. BMC Med., 15, p. 14. https://doi.org/10.1186/s12916-017-0794-8

[113] Bally, L.; Thabit, H.; Hovorka, R., 2017. Glucose-responsive insulin delivery for type 1 diabetes: The artificial pancreas story. Int. J. Pharm. https://doi.org/10.1016/j.ijpharm.2017.12.022

[114] Moher, D.; Liberati, A.; Tetzlaff, J.; Altman, D.G.; Group, P., 2010. Preferred reporting items for systematic reviews and meta-analyses: The PRISMA statement. Int. J. Surg., 8, pp. 336-341. https://doi.org/10.1016/j.ijsu.2010.02.007

[115] Stroup, D.F.; Berlin, J.A.; Morton, S.C.; Olkin, I.; Williamson, G.D.; Rennie, D.; Moher, D.; Becker, B.J.; Sipe, T.A.; Thacker, S.B.; et al., 2000, Meta-analysis of Observational Studies in EpidemiologyA Proposal for Reporting. JAMA, 283, pp. 2008-2012.

https://doi.org/10.1001/jama.283.15.2008

[116] Higgins, J.P.T.; Altman, D.G.; Gøtzsche, P.C.; Jüni, P.; Moher, D.; Oxman, A.D.; Savović, J.; Schulz, K.F.; Weeks, L.; Sterne, J.A.C., 2011. The Cochrane Collaboration's tool for assessing risk of bias in randomized trials. BMJ, 343, p. d5928. https://doi.org/10.1136/bmj.d5928

[117] Boughton, C.K.; Bally, L.; Martignoni, F.; Hartnell, S.; Herzig, D.; Vogt, A.; Wertli, M.M.; Wilinska, M.E.; Evans, M.L.; Coll, A.P.; et al., 2019. Fully closed-loop insulin delivery in inpatients receiving nutritional support: A two-center, openlabel, randomized controlled trial. Lancet Diabetes Endocri., 7, pp. 368-377. https://doi.org/10.1016/S2213-8587(19)30061-0

[118] Olveira, G.; Abuin, J.; Lopez, R.; Herranz, S.; GarciaAlmeida, J.M.; Garcia-Malpartida, K.; Ferrer, M.; Cancer, E.; Luengo-Perez, L.M.; Alvarez, J.; et al. Regular insulin added to total parenteral nutrition vs. subcutaneous glargine in noncritically ill diabetic inpatients, a multicenter randomized clinical trial: INSUPAR trial. Clin. Nutr. 2019.

[119] Hakeam, H.A.; Mulia, H.A.; Azzam, A.; Amin, T., 2017. Glargine Insulin Use Versus Continuous Regular Insulin in Diabetic Surgical Noncritically III Patients Receiving Parenteral Nutrition: Randomized Controlled Study. JPEN, 41, pp. 1110-1118 https://doi.org/10.1177/0148607116644710

[120] Lidder, P.; Flanagan, D.; Fleming, S.; Russell, M.; Morgan, N.; Wheatley, T.; Rahamin, J.; Shaw, S.; Lewis, S., 2010. Combining enteral with parenteral nutrition to improve postoperative glucose control. Br. J. Nutr., 103, pp. 16351641.

https://doi.org/10.1017/S0007114509993631

[121] Tiyapanjanit, T.; Boonyavarakul, A., 2014. Comparative study between the Phramongkutklao's diabetic blenderized diets and commercial diabetic diets on glycemic variability in 
continuous tube fed patients with type 2 diabetes. J. Med. Assoc. Thai., 97, pp. 1151-1156.

[122] Leon-Sanz, M.; Garcia-Luna, P.P.; Sanz-Paris, A.; GomezCandela, C.; Casimiro, C.; Chamorro, J.; Pereira-Cunill, J.L.; Martin-Palmero, A.; Trallero, R.; Martinez, J.; et al., 2005. Glycemic and lipid control in hospitalized type 2 diabetic patients: Evaluation of 2 enteral nutrition formulas (low carbohydrate-high monounsaturated fat vs. high carbohydrate). JPEN, 29, pp. 21-29. https://doi.org/10.1177/014860710502900121

[123] Li, F.F.; Zhang, W.L.; Liu, B.L.; Zhang, D.F.; Chen, W.; Yuan, L.; Chen, M.Y.; Zhai, X.F.; Wu, J.D.; Su, X.F.; et al., 2018. Management of glycemic variation in diabetic patients receiving parenteral nutrition by continuous subcutaneous insulin infusion (CSII) therapy. Sci. Rep., 8, p. 5888 https://doi.org/10.1038/s41598-018-24275-5
[124] Kruyt, N.D.; Biessels, G.J.; Vriesendorp, T.M.; Devries, J.H.; Hoekstra, J.B.; Elbers, P.W.; Kappelle, L.J.; Portegies, P.; Vermeulen, M.; Roos, Y.B., 2010. Subjecting acute ischemic stroke patients to continuous tube feeding and an intensive computerized protocol establishes tight glycemic control. Neurocrit. Care, 12, pp. 62-68.

https://doi.org/10.1007/s12028-009-9230-z

[125] Korytkowski, M.T.; Salata, R.J.; Koerbel, G.L.; Selzer, F.; Karslioglu, E.; Idriss, A.M.; Lee, K.K.; Moser, A.J.; Toledo, F.G., 2009. Insulin therapy and glycemic control in hospitalized patients with diabetes during enteral nutrition therapy: A randomized controlled clinical trial. Diabetes Care, 32, pp. 594-596.

https://doi.org/10.2337/dc08-1436

DOI: https://doi.org/10.15379/2410-1869.2021.08.02.05

(c) 2021 Alireza Heidari; Licensee Cosmos Scholars Publishing House.

This is an open access article licensed under the terms of the Creative Commons Attribution Non-Commercial License

(http://creativecommons.org/licenses/by-nc/3.0/), which permits unrestricted, non-commercial use, distribution and reproduction in any medium, provided the work is properly cited. 